\title{
Experimental investigation on the combined effect of dowel misalignment and cyclic wheel loading on dowel bar performance in JPCP
}

DOI:

10.1016/j.engstruct.2018.07.052

\section{Document Version}

Accepted author manuscript

Link to publication record in Manchester Research Explorer

Citation for published version (APA):

Al-Humeidawi, B. H., \& Mandal, P. (2018). Experimental investigation on the combined effect of dowel misalignment and cyclic wheel loading on dowel bar performance in JPCP. Engineering Structures, 174. https://doi.org/10.1016/j.engstruct.2018.07.052

\section{Published in:}

Engineering Structures

\section{Citing this paper}

Please note that where the full-text provided on Manchester Research Explorer is the Author Accepted Manuscript or Proof version this may differ from the final Published version. If citing, it is advised that you check and use the publisher's definitive version.

\section{General rights}

Copyright and moral rights for the publications made accessible in the Research Explorer are retained by the authors and/or other copyright owners and it is a condition of accessing publications that users recognise and abide by the legal requirements associated with these rights.

\section{Takedown policy}

If you believe that this document breaches copyright please refer to the University of Manchester's Takedown Procedures [http://man.ac.uk/04Y6Bo] or contact uml.scholarlycommunications@manchester.ac.uk providing relevant details, so we can investigate your claim.

\section{OPEN ACCESS}




\section{Manuscript Details}

\section{Manuscript number}

Title
ENGSTRUCT_2017_1737_R1

Experimental investigation on the combined effect of dowel misalignment and cyclic wheel loading on dowel bar performance in JPCP

\section{Article type}

Research Paper

\section{Abstract}

A number of previous studies indicated that the joint lockup due to misalignment and looseness of dowel bars may cause joint distress in Jointed Plain Concrete Pavement (JPCP). This article reports a detailed experimental investigation of pull-out load and joint lockup due to dowel misalignment; and dowel looseness caused by the combined effect of misalignment and cyclic traffic load. The test slabs were supported on steel beams with an appropriate amount of vertical stiffness so as to incorporate the effects of underlying layers of real pavements. The article also provides an experimental investigation to assess the suitability of Glass Fibre Reinforced Polymer (GFRP) bars as alternative dowel bars to reduce joint lockup and associated detrimental effects at the dowel-concrete interface compared with epoxy-coated steel dowels. The results show that the $38 \mathrm{~mm}$ GFRP dowels that have equivalent flexural rigidity (EI) to $25 \mathrm{~mm}$ steel dowels can withstand the cyclic traffic load, significantly reduce joint lockup and dowel looseness, and can provide adequate Load Transfer Efficiency (LTE). It was also observed that misalignment affects dowel looseness significantly more than the number of cycles for traffic load. The slab-base separation and orientation of misaligned dowels have significant effects on the load required to open the joint.

\section{Keywords}

Taxonomy

Manuscript region of origin

Corresponding Author

Corresponding Author's Institution

Order of Authors

Suggested reviewers
Experimental test; Dowel misalignment; GFRP; Dowel bars; Load Transfer Efficiency (LTE); Dowel looseness; Relative Deflection (RD).

Roadway Design, Cyclic Loads, Road Construction

Europe

Parthasarathi Mandal

University of Manchester

Basim Al-Humeidawi, Parthasarathi Mandal

Haider Habeeb Aodah, Imad AI-Qadi, Ramachandra Lingadahally, Tim Ibell 


\section{Highlights}

- Experiments to assess the suitability of GFRP as alternative to steel dowels in JPCP

- Investigate the effect of dowel misalignment under realistic pavement representation

- The results show a better overall performance of $38 \mathrm{~mm}$ GFRP dowels compared to $25 \mathrm{~mm}$ steel dowels with equivalent flexural rigidity $(E I)$.

- GFRP dowels significantly reduce joint lockup and dowel looseness

- Misalignment magnitude and orientations affect pull-out load considerably 


\section{Experimental investigation on the combined effect of dowel misalignment and cyclic wheel loading on dowel bar performance in JPCP}

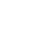

\section{Basim H. Al-Humeidawi ${ }^{1}$ and Parthasarathi Mandal ${ }^{*}$}

${ }^{1}$ Assist. Prof., Roads and Transport Department, College of Engineering, University of AlQadisiyah, Al-Diwaniyah Province, Iraq, E-mail:Basim.alhumeidawi@qu.edu.iq

${ }^{2}$ Reader, School of Mechanical Aerospace and Civil Engineering, University of Manchester, M13 9PL, Manchester, UK, E-mail: P.Mandal@manchester.ac.uk *Corresponding Author, Tel: +44 161 3064622, Email: P.Mandal@manchester.ac.uk

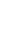

\section{ABSTRACT}

A number of previous studies indicated that the joint lockup due to misalignment and looseness of dowel bars may cause joint distress in Jointed Plain Concrete Pavement (JPCP). This article reports a detailed experimental investigation of pull-out load and joint lockup due to dowel misalignment; and dowel looseness caused by the combined effect of misalignment and cyclic traffic load. The test slabs were supported on steel beams with an appropriate amount of vertical stiffness so as to incorporate the effects of underlying layers of real pavements. The article also provides an experimental investigation to assess the suitability of Glass Fibre Reinforced Polymer (GFRP) bars as alternative dowel bars to reduce joint lockup and associated detrimental effects at the dowelconcrete interface compared with epoxy-coated steel dowels. The results show that the $38 \mathrm{~mm}$ GFRP dowels that have equivalent flexural rigidity (EI) to $25 \mathrm{~mm}$ steel dowels can withstand the cyclic traffic load, significantly reduce joint lockup and dowel looseness, and can provide adequate 2 Load Transfer Efficiency (LTE). It was also observed that misalignment affects dowel looseness 
1 significantly more than the number of cycles for traffic load. The slab-base separation and

2 orientation of misaligned dowels have significant effects on the load required to open the joint.

3 Key words: Experimental test; Dowel misalignment; GFRP; Dowel bars; Load Transfer Efficiency

4 (LTE);Dowel looseness; Relative Deflection (RD).

\section{INTRODUCTION}

6 Concrete pavements suffer several types of volumetric changes and stresses after casting due to

7 thermal expansion or contraction, and concrete shrinkage. The transverse joints are introduced to

8 relieve these stresses. Almost all highway agencies around the world recommend using dowel bars

9 to transfer the load across the joints and to reduce the relative deflection (RD) of the pavements.

10 Many concrete pavement problems come from joint distress[1]. Dowel looseness and dowel 11 misalignment are two important sources of joint distress. These two phenomena have been 12 investigated previously in isolation. Dowel looseness is an enlargement of the dowel bar socket that 13 usually occurs due to repeated traffic load, wearing or corrosion of steel dowel bars[2]. Dowel 14 misalignment occurs during the construction process of the joints when the dowel bars are 15 misplaced in positions and/or orientations. The misaligned dowels restrain the slab movement by 16 locking the transverse joints; this may initiate mid-span cracks, breakage of the corners of slabs and 17 joint spalling [3].

18 Dowel misalignment can be classified into two types: (a) translational misalignment, which occurs 19 when the whole dowel bar is offset from the central plane of the concrete slab in any direction 20 (horizontally, vertically or longitudinally) but it remains parallel to the centreline of pavement; 21 (b) skew (rotational) misalignment, which occurs when the centroid of the dowel is in the correct 22 position but the dowel tilts horizontally or vertically or in both directions [4]. In practice, a 23 particular dowel bar set may contain both types of misalignment. The focus of this study is on the 
1 skew (rotational) misalignments since they lead to more restraint to the slab movement, and as a

2 result have more detrimental effect than the translational misalignments [4, 5] (see Fig.1 for some

3 types of skew misalignments).

4 The current article presents a detailed experimental investigation into the evaluation of dowel bars'

5 performance when they are subjected to the combined effect of wheel load and misalignment issues.

6 The study also evaluates the suitability of GFRP dowel bars in those problem scenarios as

7 alternative to steel dowels. GFRP is a corrosion free material and possesses low coefficient of

8 friction which may reduce joint lock-up. The experimental programme also addressed the effect of

9 vertical stiffness of the underlying layers of pavement which had been omitted in most of the

10 previous tests $[3,5,6]$.

11 PREVIOUS STUDIES

12 There are limited number of studies on the effects of dowel misalignment in the literature,

13 considering its huge detrimental effects on joints and pavement performance. Most of the previous

14 investigations focused on the determination of magnitude and types of misalignment that would

15 cause joint distress [7, 8]. Segner and Cobb (1967) tested concrete pavement sections of $1.83 \mathrm{~m}$ (6

$16 \mathrm{ft})$ wide, $1.68 \mathrm{~m}(5.5 \mathrm{ft})$ long and $0.25 \mathrm{~m}(10 \mathrm{in})$ thick. Their results showed that the load required to

17 open the joint increased noticably for the misalignment magnitude greater than $6.4 \mathrm{~mm}$ compared

18 with aligned dowels.

19 Tayabji (1986) carried out laboratory tests on slab sections of $0.92 \mathrm{~m}$ (3ft) wide, $2.1 \mathrm{~m}$ (7ft) long

20 and $0.2 \mathrm{~m}, 0.25 \mathrm{~m}$ ( $8 \mathrm{in}, 10 \mathrm{in})$ thick with sets of one and two dowels. The tests involved

21 misalignment levels of $0,3.2,6.4,12.7,25.4$ and $50.8 \mathrm{~mm}$ per half-length of dowel (225 mm). The

22 results showed no signifcant difference in pull-out load for single misaligned dowel specimens,

23 whereas a significant increase in pull-out load was observed for the specimens containing two 
misaligned dowels when the misalignment magnitude exceeded $12.7 \mathrm{~mm}$ per half dowel length.It should be noted that there are multiple dowels bars along a typical transverse joint and the interaction effect during pull-out can not be ignored [9].

Prabhu et al. $[5,10,11]$ carried out experimental as well as numerical investigations to produce guidelines for allowable dowel misalignment. Their investigations involved one, two, three and five $32 \mathrm{~mm}$ diameter steel dowel bars with different misalignment magnitudes $(0,6.35,12.7,19$, and $25.4 \mathrm{~mm}$ per half-length of the dowel bar) and different misalignment types (vertical, horizontal and combined). The results showed that all joints in a concrete pavement start initial slipping when the load per dowel exceeds 5 to $7 \mathrm{kN}$. They also concluded that in general the joint-opening load per dowel increases for an increase in the magnitude and non-uniformity of dowel misalignment. However, in their test arrangement the slabs were fixed to the foundation, restricting any separation between the slab and the bottom layer of pavement that may happen in reality during an event of joint opening or closing. For this reason, there was insignificant difference between the loads required to open the joint for vertical and horizontal misalignments. The current set of experiments was designed by allowing for possible base separation and the effect it may have on the pull-out load.

Hoegh and Khazanovich recently carried out experimental and numerical investigations to study the effect of dowel misalignment on LTE [6, 12]. The test consisted of a concrete beam $(457 \times 1200 \times 203 \mathrm{~mm})$ fitted with four $38 \mathrm{~mm}$ round steel dowel bars (greased and ungreased) Each bar was $457 \mathrm{~mm}$ long, of which $229 \mathrm{~mm}$ was embedded in concrete with different levels of misalignment. The dowels were pulled out individually in the longitudinal direction for $6.4 \mathrm{~mm}$ (0.25 inch) and the pull-out force versus displacement was recorded. The shear capacity of the dowel bar was evaluated by turning the beam on its side and applying direct shear on the nonembedded part of the dowels. Their results suggested that dowel misalignment has an insignificant effect on the pull-out load required to open the joint $[6,12]$. Since the test arrangement is similar to 
1 a direct pull-out test for individual dowels, no interaction among the misaligned dowel bars was

2 possible. Hence the test arrangement was not representative of actual slab-openings in the field.

3 Also, the casting of the specimens in a vertical direction may have reduced the variations in

4 shrinkage strains for different dowel orientations[13, 14], which is an important factor in the

5 development of bond strength. The test arrangement excluded the possibility of additional bearing

6 stress arising due to constrained movement of the adjacent dowels. However for higher

7 misalignment magnitude, the results showed lower shear capacity for the dowel bar and more

8 deterioration of the surrounding concrete.

9 GFRP dowels as a non-corrodible dowel bars can be considered as a practical alternative to steel 10 dowel bars in JPCP especially in harsh environmental conditions. Several studies have been 11 conducted on GFRP dowels as load transfer devices in concrete pavements [15-18]. These studies 12 investigated, both experimentally and theoretically, JPCP with GFRP dowels for static and cyclic 13 load. Their results found that the GFRP dowels are adequate as load transfer devices when proper 14 diameter and spacing are selected. The authors recently published two articles (experimental study 15 and numerical simulation) evaluating the performance of GFRP dowel bars in JPCP and provided a 16 design consideration guideline $[19,20]$. The experimental results showed that GFRP dowels can 17 perform similar to steel dowels if they have equivalent flexural rigidity $(E I)$. The Numerical results 18 investigated the magnitude and distribution of bearing stress underneath both types of dowels for 19 various pavement system parameters. It should be noted here that a couple of previous studies 20 reported that the GFRP bars being highly water absorbent may cause an increase in bar diameter 21 and degradation in mechanical properties [21, 22]. However, an experimental programme that had 22 been conducted on GFRP dowels taken from a pavement section constructed by the Ohio 23 Department of Transportation and Civil Engineering (after 15 years of field service) demonstrated 24 that the dowels had been virtually unaffected with no significant decrease in mechanical properties 25 [23]. Robert et al. [24] carried out a durability test of GFRP dowels by measuring their mechanical 
1 properties after immersing in water at $60^{\circ} \mathrm{Cfor} 75$ days. The results showed that the aging process

2 produced an insignificant effect on the shear and flexural strengths. Other durability investigation

3 [25] on GFRP dowels showed a superior long term performance for vinylester-based GFRP dowels

4 (used in this study) compared to the polyester-based ones.

5 In summary, there is a clear need to study the effect of cyclic traffic loading on misaligned dowel-

6 pavement system, and to assess any increase in dowel looseness and reduction in Load Transfer

7 Efficiency (LTE), which has not been addressed before. Experiments with single misaligned dowel

8 bars do not include important interactions between the dowels in a real pavement. Besides the

9 magnitude and type of misalignment, the stiffness of the experimental slabs in the vertical direction

10 is an important aspect to consider. Also allowing the slab to separate from the base would have

11 markedly different effects on vertical misalignment compared to horizontal misalignment. This

12 aspect has not been considered adequately in previous studies. Finally, the use of GFRP dowels has

13 been reported in the literature, primarily for their non-corrodible properties. However a very limited

14 amount of research has been published on the effect of misalignment of GFRP dowels and how do

15 they compare with the misaligned steel dowels of equivalent flexural rigidity.

\section{EXPERIMENTAL SETUP}

18 The experimental work was conducted in the Heavy Structures Laboratory of University of

19 Manchester [26]. Eight specimens were tested, six of which were fitted with GFRP dowels and two

20 were fitted with epoxy-coated steel dowels (see Table 1 for details). Each test specimen consisted of

21 two concrete slabs connected by steel or GFRP dowel bars. These two slabs were separated by

$223 \mathrm{~mm}$ smooth steel plate during the concrete casting. Appropriate holes and slots were made in the

23 separation plate to allow for the dowels to connect the slabs across the joint and also to facilitate the 
1 removal of the plate itself after the following day of casting. The dimensions of the slabs were 900

$2 \mathrm{~mm} \times 900 \mathrm{~mm} \times 200 \mathrm{~mm}$ for specimens containing two dowel bars and $900 \mathrm{~mm} \times 1200$

$3 \mathrm{~mm} \times 200 \mathrm{~mm}$ for the specimens containing three dowel bars. The dowel bars used in the test were

4 of two types: (a) $25 \mathrm{~mm}$ diameter, round, smooth, fully epoxy-coated steel bars for which one half

5 of the length was greased as well; and (b) $38 \mathrm{~mm}$ GFRP dowels. All the dowels were $458 \mathrm{~mm}$ long.

6 These dowels were embedded for equal lengths $(227.5 \mathrm{~mm})$ on each side of the joint. The thickness

7 of the slabs and the dimensions of the steel dowels were selected according to the general guideline

8 of AASHTO (1993). The diameter of the GFRP dowels was chosen to get an equivalent flexural

9 rigidity $(E I)$ to the steel dowel bars. The tests have been carried out for the slabs having two and

10 three dowel bars to incorporate the effect of adjacent dowels.

11 The concrete mix design was carried out following the methods of normal concrete mix design

12 outlined in [27]. The mix ratio (cement: fine aggregate: coarse aggregate) was 1:1.5:2.6 and

13 water/cement ratio of 0.55 . This mix design was for a nominal concrete compressive strength of 28

$14 \mathrm{MPa}$ at 28 days. However, the average measured concrete compressive strength was $33 \mathrm{MPa}$ at 28

15 days.

16 The slab-moulds were manufactured with $18 \mathrm{~mm}$ thick plywood except for the cut boxes' sides

17 which were of $36 \mathrm{~mm}$ thick plywood (see Fig.2). Cut boxes were made at both sides of the mould to

18 make grooves to hold the hydraulic jacks while pushing the slab apart to create the required joint

19 opening.Four other hydraulic jacks were inserted between the frame of the machine and the slabs to

20 push back the slabs during the closing of the joint. Small grooves were also made at the base and

21 sides of the mould to fix the $3 \mathrm{~mm}$ thick separating plate. The slots in the separating plate beneath

22 the dowels were closed using sticky plastic tape before pouring concrete. The plate was kept in the

23 specimens until the concrete initially set and then it was removed (next day) by carefully pulling it

24 in vertical direction. The sticky tape underneath the dowels was later removed when the slab was

25 being lifted for testing. 
1 The dowel bars were held at their positions at the mid-depth of the specimen at a spacing of

$2300 \mathrm{~mm}$ before and during the casting process using $8 \mathrm{~mm}$ diameter smooth steel bars with $40 \mathrm{~mm}$

3 threaded ends. Both ends of each dowel bar were drilled and threaded to $40 \mathrm{~mm}$. The steel bars

4 were connected to the ends of the dowel bars and to the holes at the sides of the mould (see Fig.2).

5 These bars were coated with thick layer of grease so that they could be easily removed from the

6 specimens on the day following the casting of the concrete. To achieve the required misalignment

7 magnitude and orientation, holes were drilled at appropriate locations on the sides of the mould that

8 held the steel bars in place. The misalignment magnitude and orientation were checked after

$9 \quad$ installing the dowels and before casting.

10 In order to consider the case of an actual pavement resting on the ground, a supporting base-system

11 with equivalent foundation stiffness for the test slab was designed (see Fig.3).This consisted of four

12 transverse beams simply supported on two longitudinal beams (see Fig. 3(c)) resting on a strong

13 floor in the Heavy Structures Laboratory. The supporting beams were designed using two sets of

14 Finite Element (FE) analyses to represent a base layer with subgrade reaction modulus (stiffness) of

$1554 \mathrm{MN} / \mathrm{m}^{3}[28]$. In the first $\mathrm{FE}$ analysis, the test slab was supported by an elastic foundation which

16 also allowed any slab-base separation. In the second FE analysis the test slab was supported by four

17 beams with the arrangements shown in Fig. 3(c); interactions between the slab and the transverse

18 beams were modelled by surface to surface contact. The dimensions of the beams were selected

19 such that the deflections of the slabs at eight LVDT positions (Fig. 4) and the shear force and

20 bending moment in the dowels would be of similar values in both the analyses. Subsequently, the

21 second FE model was checked using the displacement values from the experiments. The interior

22 beams were UB $127 \times 76 \times 13$ while the outer beams were UB $152 \times 89 \times 16$. The clear length of

23 these beams was $2000 \mathrm{~mm}$. These long beams acted as equivalent spring supports underneath the

24 specimen. A similar arrangement was found in literature in evaluation of load transfer mechanism

$25[2,15]$. To minimize the effect of friction between the steel base and concrete slab on the load 
1 required to open the joint, a $1.5 \mathrm{~mm}$ thick layer of Polytetrafluoroethylene (PTFE) was used

2 underneath and on the sides of the slabs. Any in-plane rotation that may have occurred during the

3 slab movement was prevented by clamping the slabs as shown inFig.3.Thisbase arrangement

4 allowed slab-base separation during the slab movement. The amount of separation that may have

5 occurred depends on the orientation of the misaligned dowel bars.

6 In order to achieve the objectives of the current study, different types and magnitudes of 7 misalignment were considered. These cases involved aligned dowels as well as vertically non8 uniform, horizontally non-uniform, and partially misaligned dowels (see Fig.1). Three values of 9 misalignment were chosen: zero misalignment, $12.5 \mathrm{~mm}$ and $25 \mathrm{~mm}$ per half-length of the dowel 10 bar (see Table1). The first value was selected to represent the typical installation of aligned dowel 11 bars at the transverse joints without any construction error. The second value was adopted to 12 represent misalignment magnitude more than the permissible limits according to the most highways 13 agencies [29]. Also, this selection was made to keep the distress surrounding the dowel bar 14 localized without significant cracking during opening of the joint by $12 \mathrm{~mm} \mathrm{[10]} \mathrm{to} \mathrm{allow} \mathrm{for} \mathrm{the}$ 15 evaluation of LTE under cyclic load, after the slabs were pulled out and pushed back representing 16 slab movement. Previous studies $[5,10,11]$ showed that $12.5 \mathrm{~mm}$ misalignment (per half-length of 17 the dowel) did not cause global failure of specimen. The third value of misalignment magnitude (25 $18 \mathrm{~mm}$ ) was adopted to investigate the effect of high misalignment magnitude as well as failure 19 mechanism of the specimens due to joint lockup.

20 Although the $12 \mathrm{~mm}$ joint opening that has been considered in the tests is greater than the typical 21 movement of joints $(6.4 \mathrm{~mm})$ in JPCP[30], this may occur due to construction of long slabs or 22 locking up of some joints.For a particular slab, this high level of opening (12 $\mathrm{mm})$ represents the 23 worst case combined scenario of concrete contraction due to extreme temperature variation, 24 concrete shrinkage (as a result of high water content, or poor aggregate gradation, or using certain 
1 types of additives). Keeping that in mind, comparisons were also made at joint opening of $3 \mathrm{~mm}$ 2 and $6 \mathrm{~mm}$.

\section{Test sequence}

4 The experimental programme was conducted in four major steps as follow:

5 1. Step one involved deflection measurement under a static wheel load of $40 \mathrm{kN}$. This load is 6 equivalent to a single axle load according to the AASHTO [30] guide and BS 7533-12[31].

2. The second step consisted of recording the load required to open the joint by $12 \mathrm{~mm}$ when the slabs were pushed apart by two hydraulic jacks, and then pushed back to the original position.

3. The third step involved repeating the deflection measurement similar to that taken in Step one under a static wheel load of $40 \mathrm{kN}$.

4. The fourth step involved applying the $40 \mathrm{kN}$ load for one million cycles to compare the effect of the cyclic wheel load on the GFRP dowels with that of the steel dowel bars and also the effects of dowel misalignment and joint lockup on the long term performance for both types of dowel.

The specimens were instrumented as shown in Fig.3 and Fig.4. The vertical deflections of the specimens were measured using LVDTs at 8 locations in two rows parallel to the dowel bar centre

17 line as shown in Fig.4. The testing machine consisted of two controlled loading actuators held by 18 transverse beams connected to the machine frame. A thick steel plate $200 \mathrm{~mm} \times 345 \mathrm{~mm} \times 40 \mathrm{~mm}$ 19 was attached to each actuator in order to apply the $40 \mathrm{kN}$ load as a dual wheel load of single 20 equivalent axle load. The dimensions of the loaded area were selected to produce a tyre inflation 21 pressure of $580 \mathrm{KPa}$ as recommended by Huang[32].

22 The static load was applied on one side of the slab monotonically from $0.5 \mathrm{kN}$ to $40.5 \mathrm{kN}$ while the 23 other side was clamped by the second actuator which applied a nominal $0.5 \mathrm{kN}$ load on the 24 unloaded side of the specimen to prevent any possible upward movement. The deflection data for 
1 the slab were recorded during the load application. The relative deflections of the joint faces were 2 calculated and then the LTE and the dowel looseness were computed from the deflection values.

3 The concrete slabs involved in the current experimental programme were fitted with steel and 4 GFRP dowel bars with different orientations, misalignment types and misalignment magnitudes, 5 and with different numbers of dowels in the specimens. The two halves of the specimens were 6 pushed apart using two hydraulic jacks connected to one main pump to create a $12 \mathrm{~mm}$ additional 7 joint opening. These jacks applied the load as pressure on the steel plates attached to the specimen's 8 sides in order to distribute the load on them. The loading rate was $0.5 \mathrm{~mm} / \mathrm{min}$. The load required to 9 open the joint was recorded during this step. The load created by each jack was measured using load 10 cells attached to the jack, while the joint opening was measured using two horizontal slider LVDTs 11 attached to the top surface of the specimens as shown in Fig.3and Fig.4. After measuring the load 12 required to open the joint, the slabs were pushed back to maintain the initial joint opening by 13 inserting a $3 \mathrm{~mm}$ thick separator plate which was used during casting. The relative deflection (RD) 14 of the joint was measured again under the same static load $(40 \mathrm{kN})$ to show the effect of dowel 15 misalignment and joint lockup on dowel looseness and LTE. Since any increase in RD is most 16 likely related to the deterioration of concrete pavement system behaviour around the dowel, the 17 dowel looseness was assumed to be equal to the increase in RD before and after the slab 18 movement[15].

19 Since a slab movement occurs immediately after concrete casting due to concrete shrinkage and 20 changes in hydration temperature (before opening a road to traffic), this movement was applied in 21 the test specimens before starting the cyclic load test. Although the expansion and contraction of 22 slabs are a continuous process during a pavement's life, in the experimental programme it was 23 carried out only once at the start, since the objective of the study was to obtain a clear picture of the 24 difference between the looseness due to slab movement and the looseness generated due to cyclic 25 load. 
1 The last step of the test included an evaluation of the long term performance of GFRP and steel

2 dowel bars in JPCP under cyclic load. The combined effect of dowel looseness due to slab

3 movement (representation of thermal movement and shrinkage) and cyclic load (representation of

4 repeated traffic load) on LTE was investigated in this step. The cyclic load was applied as a

5 sinusoidal function on both the slabs in order to represent truck wheel load passing the joint. The

6 load amplitudes ranged between $0.5-40.5 \mathrm{kN}$ and the frequency of the load application was $4 \mathrm{~Hz}$.

7 The load from either actuator was out-of-phase to each other, i.e., when one actuator was providing

8 a full load of $40.5 \mathrm{kN}$, the other actuator was providing $0.5 \mathrm{kN}$. The lower limit was set to $0.5 \mathrm{kN}$ so

9 that the actuator would restrain any upward movement. The upward movement in a real slab would

10 be counteracted by its self-weight, the effect of which is much lower for this scaled down test

11 specimen. A rubber pad of $1 \mathrm{~mm}$ thickness was placed beneath each load actuator to prevent any

12 crushing of concrete during the cyclic load and to produce a more realistic load distribution.

13 Deflections of the concrete slabs were measured under $40 \mathrm{kN}$ static load after (i) 250,000 (ii)

14500,000 (iii) 750,000 and (iv) 1 million cycles of the applied $40 \mathrm{kN}$ load. All test process started

15 after 28 days of casting the concrete slabs.

16 RESULTS AND DISCUSSIONS

17 Firstly, the present set of experimental results considered appropriate foundation stiffness while

18 assessing the effect of dowel misalignment. In previous experiments reported in the literature, the

19 effects of the underlying layers have been completely ignored. The supporting base for the slabs

20 was designed to mimic the underlying layers. Secondly, the suitability of GFRP dowels was tested

21 for whether they could reduce the required pull-out load compared to the steel dowels. Finally, the

22 results of the combined effect of dowel misalignment and traffic wheels' load on dowel looseness

23 and LTE are presented.

\section{Dowel Misalignment for GFRP and steel dowel bars}


1 According to the standard pull-out load versus joint opening behaviour, debonding of the dowel

2 bars from a concrete pavement consists of two parts[11, 33]: (i) fully bonded to initial splitting part;

3 in which, the dowels are assumed fully bonded until the start of the initial slipping. The behaviour

4 during this stage is governed by the bond strength between the dowel bar and the concrete pavement

5 surrounding it, as represented by Eq.1. This equation assumes uniform bond along the whole

6 embedded length of the dowel which is not the case in practice. It has been used here nevertheless

7 as a comparison tool. Part(ii) slipping region, represents the de-bonding region which starts after

8 initial slipping. Slipping of the dowel bar starts when the dowel-concrete interface shear exceeds the

9 bond strength between the dowel bar and the surrounding concrete.

$10 \tau=\frac{F}{\pi D L}$

11 Where:

$12 \tau$ : bond stress,

$13 F$ : load per dowel bar,

$14 D$ : diameter of dowel,

$15 \quad L$ : length of dowel bar.

16 Even for the epoxy-coated steel dowel bars which are designed to have no bond with concrete 17 pavement, a small amount of bond exists due to chemical adhesion between the dowel bars and the 18 concrete, and the frictional stress due to wearing or nicking of the dowel bar coating. Unlike the 19 standard pull-out tests where the load drops significantly when the bond strength has been fully 20 mobilised, the slipping region for a slab-dowel system is characterised by the transverse interaction 21 between the dowel bars and the surrounding concrete arising from the displacement due to slab self22 weight. If there are multiple dowels across the joint, any non-uniformity in slab movement or 23 misalignment of dowels would create additional bearing stress on the concrete[34].

\section{Two misaligned dowels}


1 Figs.5 to 8 illustrate the pull-out loads required to open the joint for different cases of dowel 2 misalignment for GFRP and epoxy-coated steel bars. The general observations obtained from these 3 figures are that any dowel misalignment produces an increase in pull-out load, and the initial 4 slipping of the steel bars starts at a lower load compared to the GFRP dowels (see Figs.6 and 8).

5 The load required for initial slipping is governed by the bond strength between the dowel bar and 6 concrete. For similar bond strength the load required for initial slipping increases with higher 7 diameter as given by Eq.1. The initial slipping was considered to take place at $0.05 \mathrm{~mm}$ joint 8 opening. Also this was the smallest measured displacement achieved by the slider LVDTs with a 9 high level of certainty in the experimental test. The initial slipping of the aligned steel dowel bars 10 occurred at $2.5 \mathrm{kN}$ while for the GFRP it occurred at $4 \mathrm{kN}$, which is approximately at a similar ratio 11 of the diameters. The initial slip load value of steel dowels is comparable to what had been observed 12 in the literature[5].

13 Fig.5 shows the effect of vertical misalignment for the GFRP dowels (GA2 and GV2N2). The 14 results indicate that there is no significant difference between the specimens with aligned (GA2) 15 and misaligned dowels (GV2N2). The maximum load required to open the joint for specimenGA2 16 is $8.35 \mathrm{kN}$ while for the specimen GV2N2 it is $8.85 \mathrm{kN}$ after initial slipping. Both specimens 17 exhibited similar behaviour at the post initial-slipping stage. The load required to open the joint did 18 not change significantly at this stage for both the specimens. It showed a decreasing trend during 19 the opening of the joint where the final values at the $12 \mathrm{~mm}$ joint opening were $7.1 \mathrm{kN}$ and $7.5 \mathrm{kN}$ 20 for the specimens GA2 and GV2N2 respectively. This small difference can be explained by the fact 21 that, for non-uniform vertically misaligned dowels, part of the pulling force will be expended as 22 bearing pressure on to the dowels, which will eventually require a higher pull-out force for the same 23 amount of slip. The load-slip behaviour for the misaligned specimen was relatively smooth possibly 24 due to the relative vertical positions of the slabs at the joint being maintained by two non-uniformly 
misaligned dowels creating two opposing wedge effects. For the aligned specimen, the zigzag profile can be attributed to possible stick-slip behaviour.

Fig.6 shows pull-out load versus joint opening for aligned GFRP and steel dowels. The graphs show that, for the steel dowel bars (SA2) slip initiates at a lower load level of $2.5 \mathrm{kN}$ than that of the GFRP dowels (GA2) at $4 \mathrm{kN}$ due to smaller contact area according to the bond stress formula (Eq.1), assuming similar level of initial bond strength. The post initial-slip load for steel dowels increased until it reaches a maximum value of $10.8 \mathrm{kN}$ at a joint opening of around $4 \mathrm{~mm}$. After initial slipping $(2.5 \mathrm{kN})$, the behaviour was governed by interlock friction resulting from the layer of mortar sticking to the dowel surface as observed in the post-mortem of the specimens. It is also to be noted that strain compatibility along the length of a dowel would dictate that the breaking of bond does not occur at a single instant, rather it progresses from one end. The post-initial slip behaviour for the GFRP dowels (from $4 \mathrm{kN}$ to the maximum of $8.35 \mathrm{kN}$ ) on the other hand, was less gradual as the progression of bond-breaking may have occurred at a higher rate due to smoother surface profile at micro-scale. The pull-out load increases until complete breaking of the entire bond. For the steel dowels this occurs at around $4 \mathrm{~mm}$ of joint opening, and the pull-out load starts to decrease hence forth due to lower friction coefficient arising from smoothing of the dowelconcrete interface layer with increasing slip. For the GFRP dowels, there was no evidence of layer of cement mortar sticking to the dowel surface. As a result, the last stage of the load slip behaviour did not involve further smoothing of the interface layer for increasing joint-opening.

Fig.7 illustrates the comparison of load-slip behaviour for aligned and vertically misaligned steel dowel bars (SA2 and SV2N2). Although, the misalignment of steel dowel bars and its effect on pull-out load and stress at the dowel-concrete interface had been investigated in literature, the combined effect of cyclic wheel load and dowel misalignment on the performance of the doweljoint system has not yet been explored. Also, most of the experimental programme in literature did 
1 dowel misalignment is somewhat incomplete. The testing of these specimens (SA2 and SV2N2)

2 was carried out with the aim of providing a clearer picture of steel dowel-concrete slab interaction

3 and to give a better understanding of the effect of dowel misalignment. These tests were also used

4 to investigate the detrimental effect of misalignment for GFRP dowels and a comparison was made

5 with the steel dowels (SA2 and SV2N2) of equivalent flexural rigidity.

6 The results showed a significant increase in the load per dowel required to open the joints of

7 vertically non-uniform misaligned steel dowels (SV2N2) compared with the aligned dowels (SA2).

8 The maximum load observed for SV2N2 was about $14.6 \mathrm{kN}$ compared to $10.8 \mathrm{kN}$ for SA2. These

9 loads were observed at joint opening of $3.5 \mathrm{~mm}$ to $4 \mathrm{~mm}$ which is similar to that occurs in actual

10 pavements due to temperature and moisture variations. After reaching the maximum pull-out load,

11 the reduction in pull-out load per dowel with joint opening was greater for specimen SA2 than for

12 specimens SV2N2 (as can be seen in Fig.9). In the case of aligned dowel bars, the pull-out force is

13 primarily affected by frictional stress after complete breaking of bond, whereas bearing stress is

14 also significant for misaligned dowels. Comparison of the results with GFRP dowels as shown in

15 Fig. 5, reveals that the effect of vertical misalignment is significant for steel dowels primarily due to

16 higher frictional forces. Also the bearing stress for misaligned dowels is more concentrated due to

17 smaller diameter and high transverse stiffness compared to the GFRP dowels.

18 Although there is no clear consensus among the highway agencies about the allowable pull-out load

19 in dowel bars in JPCP, the test loads for SA2 and SV2N2exceeded the allowable load stated by

20 some agencies such as Michigan Department of Transportation (MDOT) [35]. They state that the

21 allowable pull-out stress per dowel bar should be about $0.4 \mathrm{MPa}$, i.e. for the $25 \mathrm{~mm}$ diameter and 38

$22 \mathrm{~mm}$ dowel bars and embedded length of $227.5 \mathrm{~mm}$ the allowable pull-out loads are about $7 \mathrm{kN}$ and

$2311 \mathrm{kN}$ respectively. However their recommendation does not consider difference in mechanical

24 property of the dowel material. Noting that limitation, the GFRP dowels (GA2 and GV2N2) in the

25 current experiments showed lower pull-out loads than the above limits. 
1 Fig.8 presents a comparison of the results of specimens with non-uniform vertical misalignment 2 (SV2N2 and GV2N2) for both steel and GFRP dowels, and for non-uniform horizontal 3 misalignment for specimens of GFRP dowels (GH2N4). The results also show that for same type 4 and magnitude of dowel misalignment (SV2N2 and GV2N2) the steel dowels start to debond at a 5 lower load but need a significantly higher force to completely debond and slip. The initial 6 debonding of the dowel bars is affected significantly by the dowel bar diameter as mentioned 7 before, whereas the slipping of the dowels is governed by the frictional force between the dowel bar 8 and the concrete pavement, and the surface texture of the dowel. Since, the dowel-concrete interface

9 friction encountered by epoxy-coated steel dowels is much higher than the GFRP[36], any increase 10 in contact pressure due to bearing stress on the dowel bar produces a noticeable increase in the load 11 required to open the joint. The maximum pull-out load for specimenSV2N2 can be observed at an 12 approximately $4 \mathrm{~mm}$ joint opening. The load reached $14.6 \mathrm{kN}$ (twice the allowable limit stated 13 before) then decreased to a plateau value of $12.5 \mathrm{kN}$. For the specimens with GFRP dowels a 14 maximum load of $8.85 \mathrm{kN}$ was obtained after the start of slipping, then it linearly decreased to its 15 final value of $7.5 \mathrm{kN}$ at a $12 \mathrm{~mm}$ joint opening. For specimens with horizontal misalignment 16 (GH2N4), significantly higher load was needed to open the joint. Similar to the vertically 17 misaligned dowels, bearing pressure induced frictional force increases for horizontally misaligned 18 dowels too. Unlike the vertical misalignment cases, no lifting of the specimens was expected to 19 occur during the pull-out process (indicated by an FE analysis [26]).Large pull-out load was 20 required for GH2N4possibly due to the above reasons, and also the magnitude of misalignment was 21 the highest one considered in this study. Cracks were observed at the concrete surface when the 22 joint opening exceeded $6 \mathrm{~mm}$ and the concrete slab completely failed when the joint opening 23 exceeded $9 \mathrm{~mm}$.

24 In order to show the variation of the pull-out load with the joint opening, the comparison between 25 steel and GFRP was made at joint opening of $3 \mathrm{~mm}, 6 \mathrm{~mm}$ and $12 \mathrm{~mm}$ as shown in Fig.9. Although 
1 the GFRP dowels had bigger diameter compared to the steel dowels, the bar chart illustrates that

2 GFRP dowels show significantly lower pull-out load. For similar diameter, the GFRP dowels could

3 produce more reduction in pull-out load compared with steel dowels as many previous studies

4 showed that the pull-out load increases with dowel bar diameter [34, 36]. Even for joint opening of

$53 \mathrm{~mm}$, the steel dowels exhibit higher pull-out load than the allowable limit stated by Michigan

6 Department of Transportation (MDOT)[35].

\section{$7 \quad$ Three misaligned dowel bars}

8 Fig.10 presents the results of the slab specimens with three GFRP dowels:GA3, GV3P2, and

9 GH3N2.As stated in Table 1, the specimen GA3 contains three aligned dowels; in specimen GV3P2

10 the central dowel is vertically misaligned while the outer ones are aligned; and finally in specimen

11 GH3N2 the outer two dowels are non-uniformly (oppositely) misaligned and the central one is

12 aligned. The results show that the initial debond of GA3 occurred at slightly higher load than the

13 other specimens, however, at the post-initial stage the pull-out load is nearly flat with a small

14 decrease until the joint is fully opened. The behaviour is similar to GA2 and GV2N2 (Fig. 5). While

15 for specimens GV3P2, the vertical tilt of the middle dowel bar caused increased contact pressure

16 due to bearing stress which initiated the debonding process at about $6 \mathrm{kN}$ load over a small length at

17 the stress concentration location and continued to progress towards complete debonding at $5 \mathrm{~mm}$

18 joint opening. After breaking of the bond, the behaviour becomes similar to that of GA3 because the

19 pull-out load at that stage is only the load required to overcome sliding friction. For the specimen

20 GH3N2, it can be noticed from the same figure that the load required to open the joint increases

21 with higher joint opening. Also, the load magnitude (at joint opening of $6 \mathrm{~mm}$ and onward) is the

22 highest among the specimens with three GFRP dowels of different orientations. This is because no

23 slab-base separation occurs for horizontal misalignment; hence there is no possibility in the

24 reduction of contact pressure between the slab and the dowels. 
1 Relative deflection (RD) and dowel looseness due to slab movement

2 In order to investigate dowel looseness due to slab movement (expansion or contraction) and its

3 effect on LTE, the deflections of the specimens were measured under vertical static load before, and

4 after this movement. These tests were conducted to show the effect of slab movement on the

5 specimens which had epoxy-coated steel dowel bars as compared with those specimens that had

6 GFRP dowels, in order to investigate the suitability of using GFRP dowels to reduce joint lockup,

$7 \quad \mathrm{RD}$ and improve the LTE.

8 Fig.11 presents the results of the comparison between the RD for each specimen before, and after

9 the slab movement. It can be observed that for all the specimens, RD after the movement is higher

10 than its value before the movement. The increase in RD for the specimens with misaligned dowels -

11 both steel and GFRP dowels is higher than that of the specimens of aligned dowels. The specimens

12 of GFRP dowels exhibited a smaller increase in RD after the slab movement compared with those

13 of the epoxy-coated steel dowels. This is possibly due to smooth surface texture of the GFRP

14 dowels creates lower frictional forces, which leads to lower stresses at the dowel-concrete interface.

15 The dowel bar socket may deteriorate less as a result of this.

16 In addition to RD (Relative Deflection), LTE (Load Transfer Efficiency) was also used to compare

17 the performance of the steel and GFRP dowels. LTE is a criterion recommended in the AASTHO

18 (1993) guide to evaluate the load transfer by dowel bars across a pavement joint. When a load is

19 applied at the joint-face of a slab, both slabs are expected to deflect as a result of that. For an ideal

20 load transfer across the joint, both loaded and unloaded slabs should exhibit same joint-face

21 deflection. The LTE is measured as a ratio of the deflection of the unloaded side $\left(d_{u}\right)$ to the

22 deflection of the loaded side of the joint $\left(d_{l}\right)$ as shown in Eq.2

23

$L T E=\frac{d_{u}}{d_{l}} \times 100 \%$ 
1 Fig.12 shows a comparison of the LTE before, and after, the pulling out and pushing back of the

2 slabs. Since LTE was calculated as a function of joint-face deflections, a similar trend of results to

3 those in Fig.11was obtained. The reduction in LTE is smaller for specimens with aligned dowels

4 than for those with misaligned dowels. Also, the specimens with GFRP dowels exhibited a smaller

5 reduction in LTE compared with that of steel dowels. Even that the tested slabs are smaller than the

6 typical slabs which may give higher LTE than that of typical slabs, the LTE can produce an

7 indication for the change in LTE with dowels type and dowels misalignment for same size of slabs.

$8 \quad$ Results of the cyclic load test

9 The vertical deflection of the slabs was recorded under a static load of $40 \mathrm{kN}$ after each set of 10250,000 load cycles and the LTE was calculated from those readings. The results presented in

11 Fig.13 show that the $38 \mathrm{~mm}$ GFRP dowels produce a lower RD (relative deflection) compared with

$1225 \mathrm{~mm}$ epoxy-coated steel dowel bars. The RD values for specimen GV2N2show an increasing

13 trend with number of load cycles, however, they remain lower than the SV2N2 values.

14 Fig.14 illustrates LTE (Load Transfer Efficiency) values for various specimens subjected to the

15 cyclic load test. The results show a good LTE can be achieved by GFRP dowels during cyclic

16 loading, principally due to the higher diameter of GFRP dowels being used. Similar to RD in Fig.

17 13, LTE for the GFRP specimen GV2N2 decreased at a higher rate with increasing number of load

18 cycles compared to the steel specimens SV2N2. However, the LTE values still remained very high

19 and within a range of $70-100 \%$ which is adequate for the load transfer across a typical joint [30].

20 The short slab length (less than the typical slabs) and un- deteriorate and un-compacted base may be

21 the reasons of not clear monotonically decrease in LTE and remain it value more than $90 \%$.

Fig.15 shows comparison between the dowel looseness due to slab movement and that due to the

23 application of one million cycles of $40 \mathrm{kN}$ load. The dowel looseness was calculated from the 
1 growth in $\mathrm{RD}$ of the joint face (i.e. dowel looseness equals to $\mathrm{RD}$ after the slab movement minus

$2 \mathrm{RD}$ before the slab movement). The results reveal that the looseness due to slab movement is higher

3 for the steel dowels than for GFRP dowels, and for misaligned dowels than for aligned dowels

4 cases. Pulling out and pushing back the slabs during the test (as a representation of the expansion

5 and contraction of the concrete pavement) produced looseness for the epoxy-coated steel dowels

6 higher than that due to one million load cycles; whereas, for the GFRP dowels, the looseness

7 magnitude due to the slab movement is smaller than that due to the cyclic load effect. These

8 performances are associated with the surface texture of both types of these dowels. The higher

9 frictional stress between the steel dowels and the concrete causes more deterioration and looseness

10 than that for GFRP dowels. The specimen GV2N2 shows slightly greater looseness than that of

11 SV2N2 after one million cycles of $40 \mathrm{kN}$ load. The movement of slabs with misaligned dowels

12 created looseness at the joint face which consequently increases the unsupported length of the

13 dowel bar segment at the joint. This increase in unsupported length is more of a concern for GFRP

14 dowels than steel dowels because of GFRP dowels being weaker in the transverse direction. In spite

15 of this looseness, the GFRP dowel showed very high LTE (see Fig.14).

16 SUMMARY AND CONCLUSIONS

17 An experimental study has been conducted to investigate dowel misalignment and joint lockup

18 using epoxy-coated steel and GFRP dowels supported on a base-system with equivalent stiffness of

19 a real pavement system. The study considered the effects of the position of the dowel bar during

20 concrete casting; and evaluated the combined effect of dowel misalignment and cyclic traffic wheel

21 load on LTE, relative deflection and dowel looseness for epoxy-coated steel and GFRP dowels. The

22 GFRP dowels, as an alternative to epoxy-coated steel dowel bars, show a significant reduction in

23 the load required for joint opening especially for excessive joint opening. The lower pull-out load

24 reduces the stress at the dowel-concrete interface, dowel looseness and the mid-span stress in the 
1 slab. Although only one cycle of push-out and push-back was conducted, the results illustrate that

2 the axial movement of the slab produces a significant increase in dowel looseness and a decrease in

3 LTE compared with the effect due to repeated traffic load especially when dowel misalignment

4 exists. The use of GFRP dowels may improve the pavement performance by reducing the joint

5 lockup and enhancing the LTE. Since the expansion and contraction of pavements are continuous

6 during the service life of a road, more deterioration may occur in the concrete surrounding steel

7 dowels as compared to GFRP dowels. This deterioration increases rapidly when dowel

8 misalignment exists and may cause failure similar to the one witnessed in specimen GH2N4. It

9 should be mentioned that although the experiments were designed after careful considerations of

10 various parameters, the current set of results is by no means comprehensive and does not include

11 other effects like curling of slabs due to temperature changes. This will be addressed in a

12 subsequent study. The experimental results even though clearly indicate better performance of

13 GFRP dowels under the test conditions, more experimental data are necessary for detailed

14 quantitative evaluation. Despite the above limitations, it was reassuring to note that the general

15 trend of the tested specimens is consistent with the results in literature.

16 ACKNOWLEDGEMENT

17 The authors acknowledge the help and support provided by Mr John Mason and Mr Dave Mortimer

18 with the experimental work. The first author also acknowledges the financial support from the Iraq

19 Ministry of Higher Education towards his $\mathrm{PhD}$.

\section{COMPETING INTERESTS STATEMENT}

21 The authors declare no competing interests.

\section{REFERENCES}


1 [1] American Concrete Pavement Association (ACPA). Design and Construction of Joints

2 for Concrete Highways. Skokie, IL: ACPA; 1991. p. 24

3 [2] Teller LW, Cashell HD. Performance of doweled joints under repetitive loading. Public 4 Roads. 1958;30:1-24.

5 [3] Tayabji SD. Dowel placement tolerances for concrete pavements. Transportation 6 Research Record. 1986:47-54.

[4] Khazanovich L, Buch N, Gotlif A. Evaluation of alignment tolerances for dowel bars and their effects on joint performance. Michigan: Michigan State University, Pavement Research Center of Excellence; 2001.

[5] Prabhu M, Buch N, Varma AH. Experimental investigation of effects of dowel misalignment on joint opening behavior in rigid pavements Transportation Research Record. 2006:15-27.

[6] Hoegh K, Khazanovich L. Laboratory investigation of misaligned dowel behavior. Journal of Testing and Evaluation. 2009;38:127-35.

[7] Smith A, Benham S. Effect of dowel bar misalignment across concrete pavement joints. ASCE Transactions. 1938;103:1133-62.

[8] Segner E, Cobb JR. A study of misaligned dowels in concrete pavements. State of Alabama, Highway Dept., Bureau of Research and Development (Montgomery); 1967.

[9] Saxena P, Hoegh K, Khazanovich L, Gotlif A. Laboratory and analytical modelling of misaligned dowel. International Journal of Pavement Engineering. 2011:1-7.

[10] Prabhu M, Buch N, Varma AH. Analytical investigation of the effects of dowel misalignment on concrete pavement joint opening behaviour. International Journal of Pavement Engineering. 2009;10:49-62.

[11] Prabhu M, Buch N, Varma AH. Experimental and analytical investigations of mechanistic effects of dowel misalignment in jointed concrete pavements. Transportation Research Record. 2007;2037:12-29.

[12] Saxena P, Hoegh K, Khazanovich L, Gotlif A. Laboratory and Finite Element Evaluation of Joint Lockup. Transportation Research Record: Journal of the Transportation Research Board. 2009;2095:34-42.

[13] Kim JK, Lee CS. Prediction of differential drying shrinkage in concrete. Cement and Concrete Research. 1998;28:985-94.

[14] Lim S, Jeong JH, Zollinger DG. Moisture profiles and shrinkage in early-age concrete pavements. International Journal of Pavement Engineering. 2009;10:29-38. 
[15] Porter M, Guinn Jr RJ, Lundy AL, Davis DD, Rohner JG. Investigation of Glass Fiber Composite Dowel Bars for Highway Pavement Slabs: Final Report. TR-408 Submitted to Highway Division of the Iowa Department of Transportation and Iowa Highway Research Board. Iowa State University, Engineering Research Institute, Ames, IA; 2001.

[16] Porter M, Hughes BW, Viswanath KP, Barnes BA. Non-Corrosive Tie Reinforcing and Dowel Bars for Highway Pavement Slabs: Progress Report. Iowa Highway Research Board Project HR-343. Ames, Iowa: Department of Civil and Construction Engineering, Iowa State University; 1993.

[17] Eddie D, Shalaby A, Rizkalla S. Glass fiber-reinforced polymer dowels for concrete pavements. ACI Structural Journal. 2001;98:201-6.

[18] Vijay PV, Hota VS, GangaRao, Li H. Design and evaluation of jointed plain concrete pavement with fiber reinforced polymer dowels. Morgantown: West Virginia University; 2009.

[19] Al-Humeidawi BH, Mandal P. Evaluation of performance and design of GFRP dowels in jointed plain concrete pavement - part 1: experimental investigation. International Journal of Pavement Engineering. 2014;15:449-59.

[20] Al-Humeidawi BH, Mandal P. Evaluation of performance and design of GFRP dowels in jointed plain concrete pavement - part 2: numerical simulation and design considerations. International Journal of Pavement Engineering. 2014;15:752-65.

[21] Nishizaki I, Meiarashi S. Long-term deterioration of GFRP in water and moist environment. Journal of Composites for Construction. 2002;6:21-7.

[22] Morii T, Hamada H, Maekawa ZI, Tanimoto T, Hirano T, Kiyosumi K et al. Weight changes of the fibre/matrix interface in GRP panels immersed in hot water. Composites science and technology. 1994;50:373-9.

[23] Busel J. Fiber-reinforced polymer(FRP) composite dowel bars-- a 15 year durability study. Plastics in Building Construction[Plast Build Constr]. 2000;25:8-12.

[24] Robert M, Cousin P, Ahmed E, Montaigu M, Benmokrane B. Performance characteristics of GFRP dowels for concrete pavement. Annual Conference of Canadian society of civil engineering CSCE. Canada2010. p. 185-94.

[25] Montaigu M, Robert M, Ahmed EA, Benmokrane B. Laboratory Characterization and Evaluation of Durability Performance of New Polyester and Vinylester E-glass GFRP Dowels for Jointed Concrete Pavement. Journal of Composites for Construction. 2013;17:176-87.

[26] Al-Humeidawi BH. Evaluation of the performance of GFRP dowels in Jointed Plain Concrete Pavement (JPCP) for Road/Airport under the Combined Effect of Dowel Misalignment and Cyclic Wheel Load Manchester University of Manchester; 2013. 
1 [27] Teychenne DC, Franklin R, Erntroy H, Nicholls J, HOBBS D, MARSH D. Design of

2 normal concrete mixes: Garston : CRC1997; 1997.

3 [28] O'Flaherty CA. Highways: The Location, Design and Maintenance of Road 4 Pavements. $4^{\text {th }}$ edition ed: Butterworth Heinemann Jordan Hill Oxford; 2002.

5 [29] UK Highway Agency. Manual of contract documents for highway works (MCHW).

6 Volume 1 specification for highway works, . London, UK: UK Highway Agency; 2009.

7 [30] AASHTO. AASHTO guide for design of pavement structure. Washington D. C.: 8 American Association of State Highway and Transportation Officials 1993.

9 [31] BS 7533-12. Pavements constructed with clay, natural stone or concrete pavers Part 10 12: Guide to the structural design of trafficked pavements constructed on a bound base 11 using concrete paving flags and natural stone slabs. London: British Standard Institution; 12 2006. p. 1-16.

13 [32] Huang Y. Pavement Analysis and Design. Prentice-Hall1993.

14 [33] Lee JY, Cheong YG, Yi CK, Kim B, II. Bond stress-slip behaviour of two common 15 GFRP rebar types with pullout failure. Magazine of concrete research. 2012;64:575-91.

16 [34] Al-Humeidawi $\mathrm{BH}$, Mandal $\mathrm{P}$. Investigation of different dowel and pavement 17 parameters on joint lockup. 5th INTERNATIONAL CONFERENCE BITUMINOUS

[35] Michigan Department of Transportation. Standard construction specifications. Section 914 joint and waterproofing materials,. Michigan, USA2012.

21 [36] Löfsjögård M. A laboratory investigation on bonding properties of dowels in concrete roads. Materials and Structures/Materiaux et Constructions. 2005;38:721-8. 


\section{List of Figures}

2 Fig.1. Different types of skew misalignment: (a) Section view, non-uniform vertical misalignment;

3 (b) Section view, uniform vertical misalignment; (c) Plane view, uniform horizontal misalignment;

4 (d) Plane view, non-uniform horizontal misalignment; (e) Plane view, partial horizontal

5 misalignment (h: slab thickness, s: dowel bars spacing, m: misalignment magnitude).

6 Fig.2. Preparations of the specimens: (a) Aligned dowels; (b) Horizontally non-uniform misaligned 7 dowels.

8 Fig.3. Actual setup for the specimen with all instrumentations: (a) Detail view; (b) Load 9 arrangement; (c) Complete setup.

10 Fig.4. Sketch of a specimen with all instrumentations.

11 Fig.5. Effect of vertical misalignment for GFRP dowels - pullout load versus joint opening for the 12 specimens GA2 and GV2N2.

13 Fig.6. Comparison of aligned GFRP and steel dowels - pullout load versus joint opening for the 14 specimens GA2 and SA2.

15 Fig.7. Effect of vertical misalignment for steel dowels - pullout load versus joint opening for the 16 specimens SA2-steel and SV2N2.

17 Fig.8. Comparison between horizontal and vertical misalignment - pullout load versus joint opening 18 for the specimens of SV2N2, GV2N2 and GH2N4.

19 Fig.9. Comparison of pull-out loads for steel and GFRP at joint opening of $3 \mathrm{~mm}, 6 \mathrm{~mm}$ and $12 \mathrm{~mm}$.

20 Fig.10. Comparison of partial vertical and horizontal non-uniform misalignment with aligned

21 dowels - pullout load versus joint opening for the specimens which have three GFRP dowels.

22 Fig.11. Comparison of relative deflection before, and after, slabs' movement.

23 Fig.12. Comparison of LTE before, and after, slabs' movement.

24 Fig.13. Relative deflection versus number of load cycles.

25 Fig.14. LTE versus number of load cycles.

26 Fig.15. Comparison of dowels' looseness due to slabs' movement and cyclic load. 


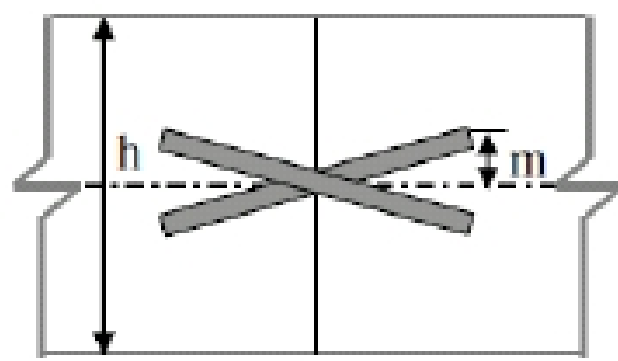

(a)

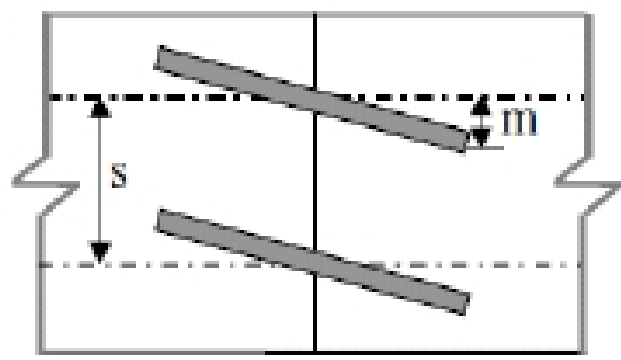

(c)

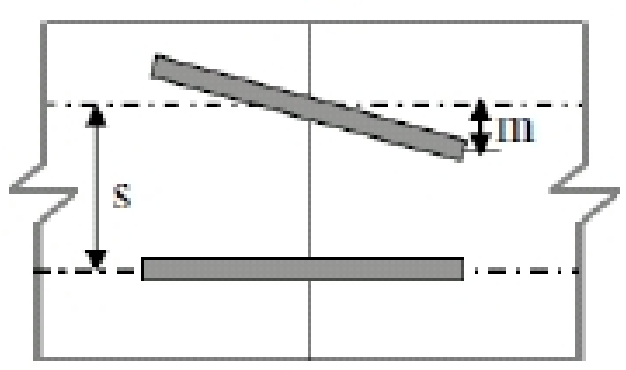

(e)

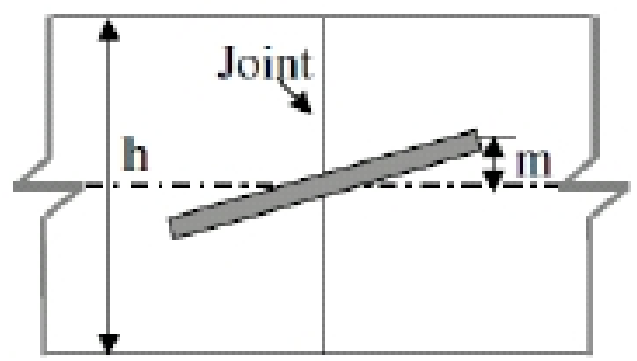

(b)

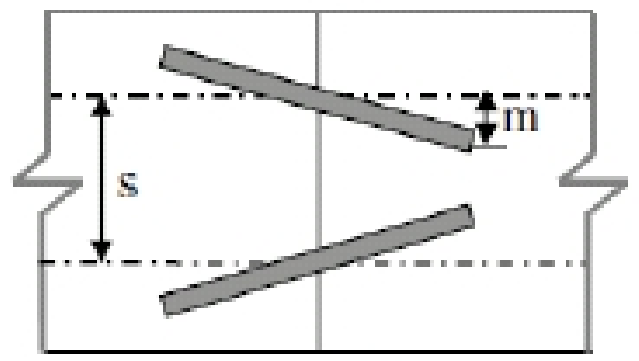

(d)

(1)

Fig.1. Different types of skew misalignment: (a) Section view, non-uniform vertical misalignment; (b) Section view, uniform vertical misalignment; (c) Plan view, uniform horizontal misalignment; (d) Plan view, non-uniform horizontal misalignment; (e) Plan view, partial horizontal misalignment (h: slab thickness, s: dowel bars spacing $\mathrm{m}$ : misalignment magnitude). 


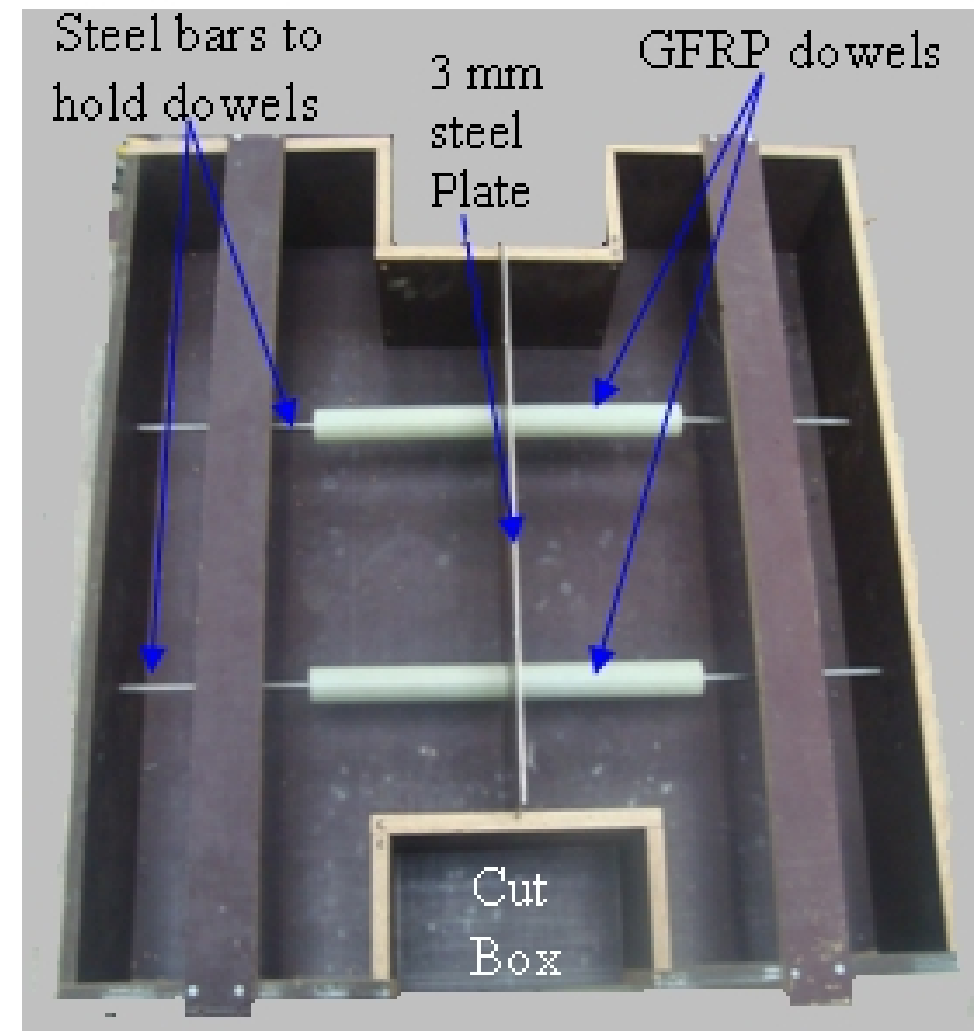

(a)

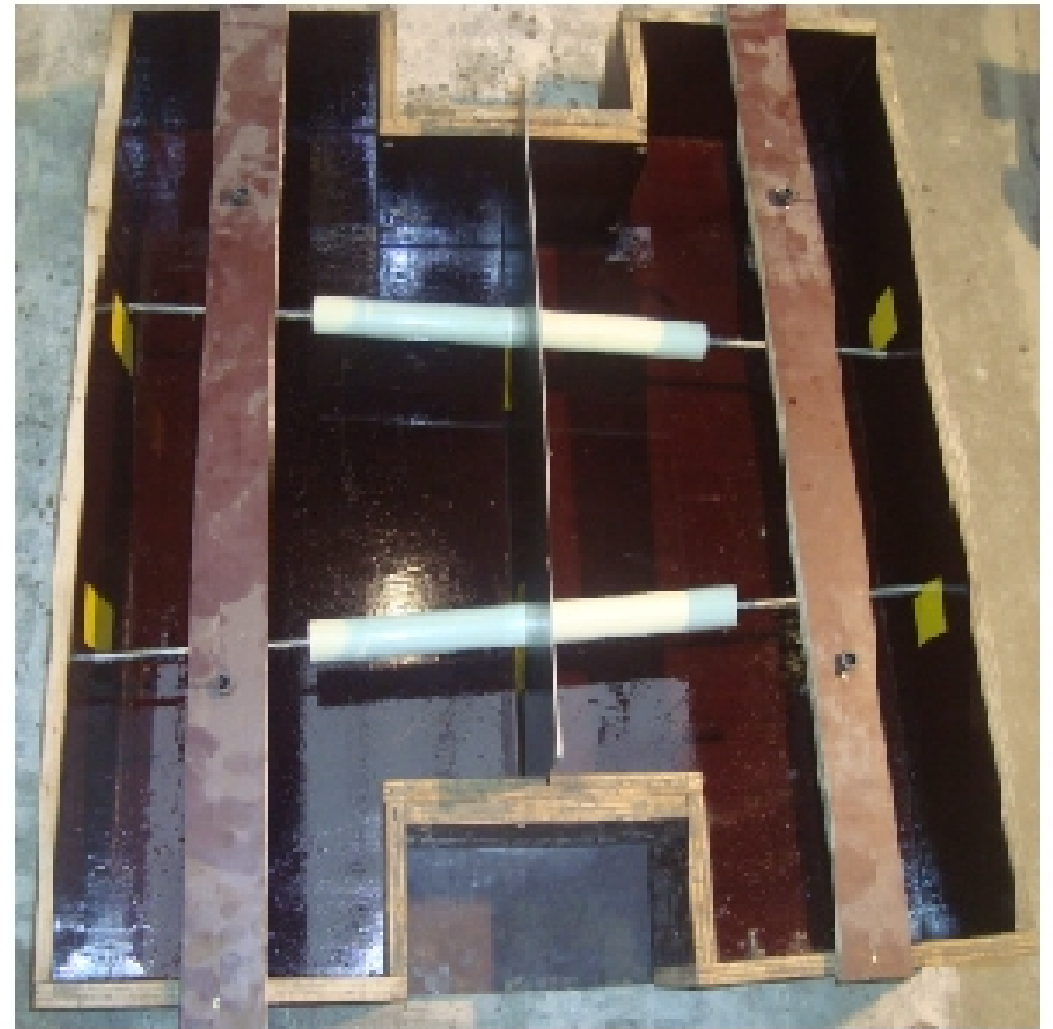

(b)

Fig.2. Preparations of the specimens: (a) Aligned dowels; (b) Horizontally non-uniform misaligned dowels. 
(a)

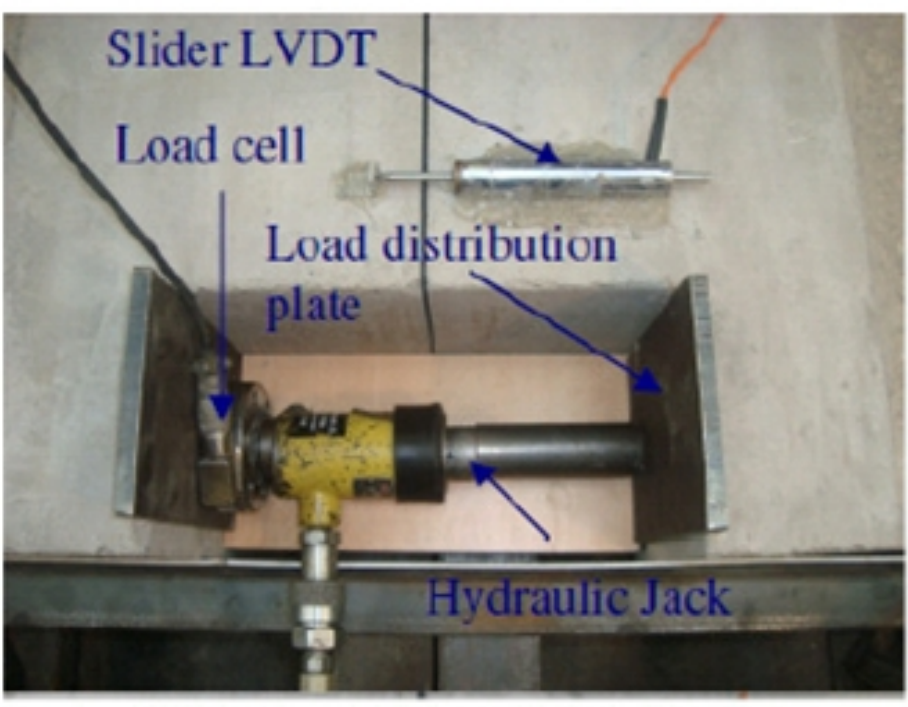

(c)

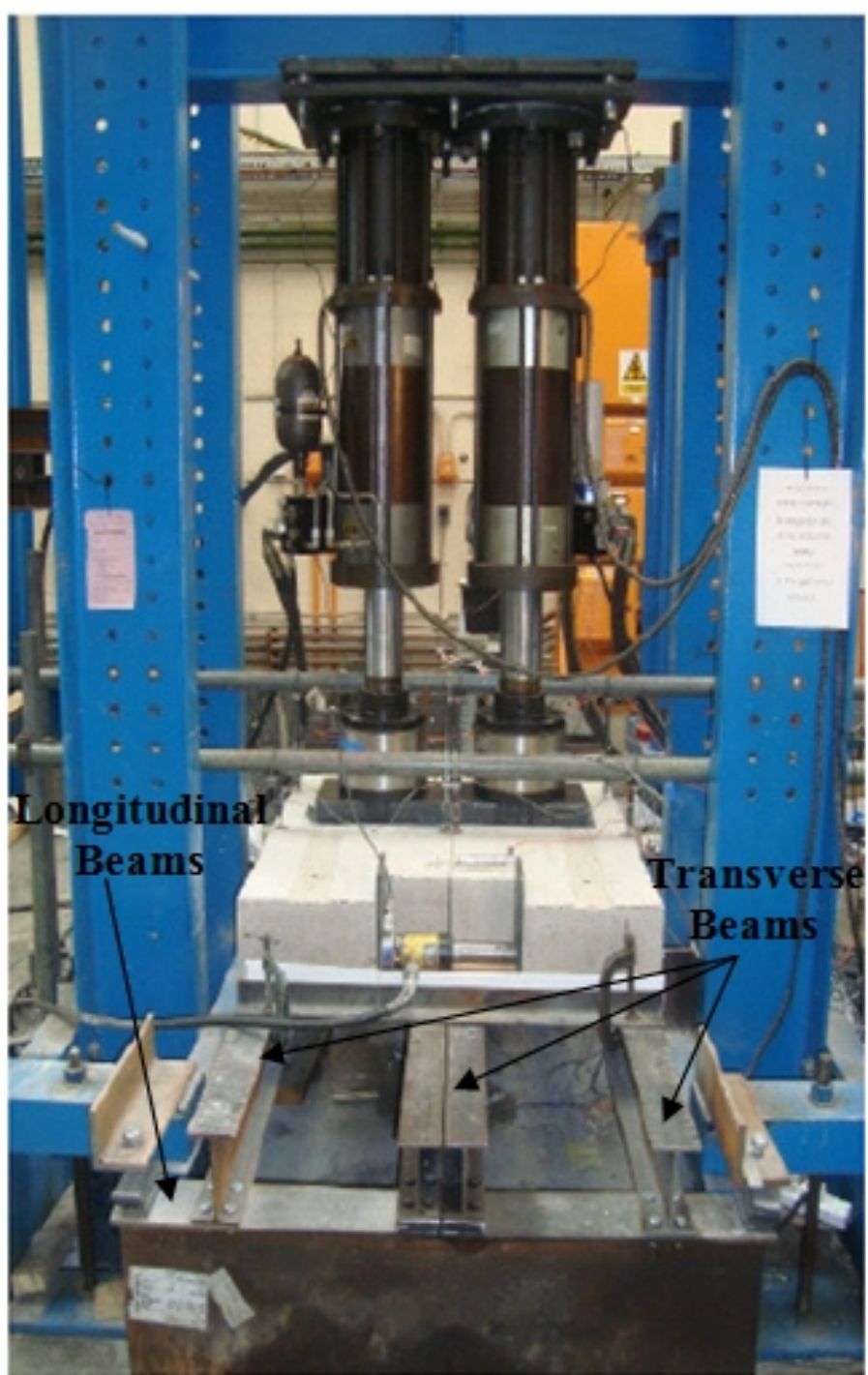

Fig.3. Actual setup for the specimen with all instrumentations.

(a) Detail view; (b) Load arrangement (c); Complete setup 


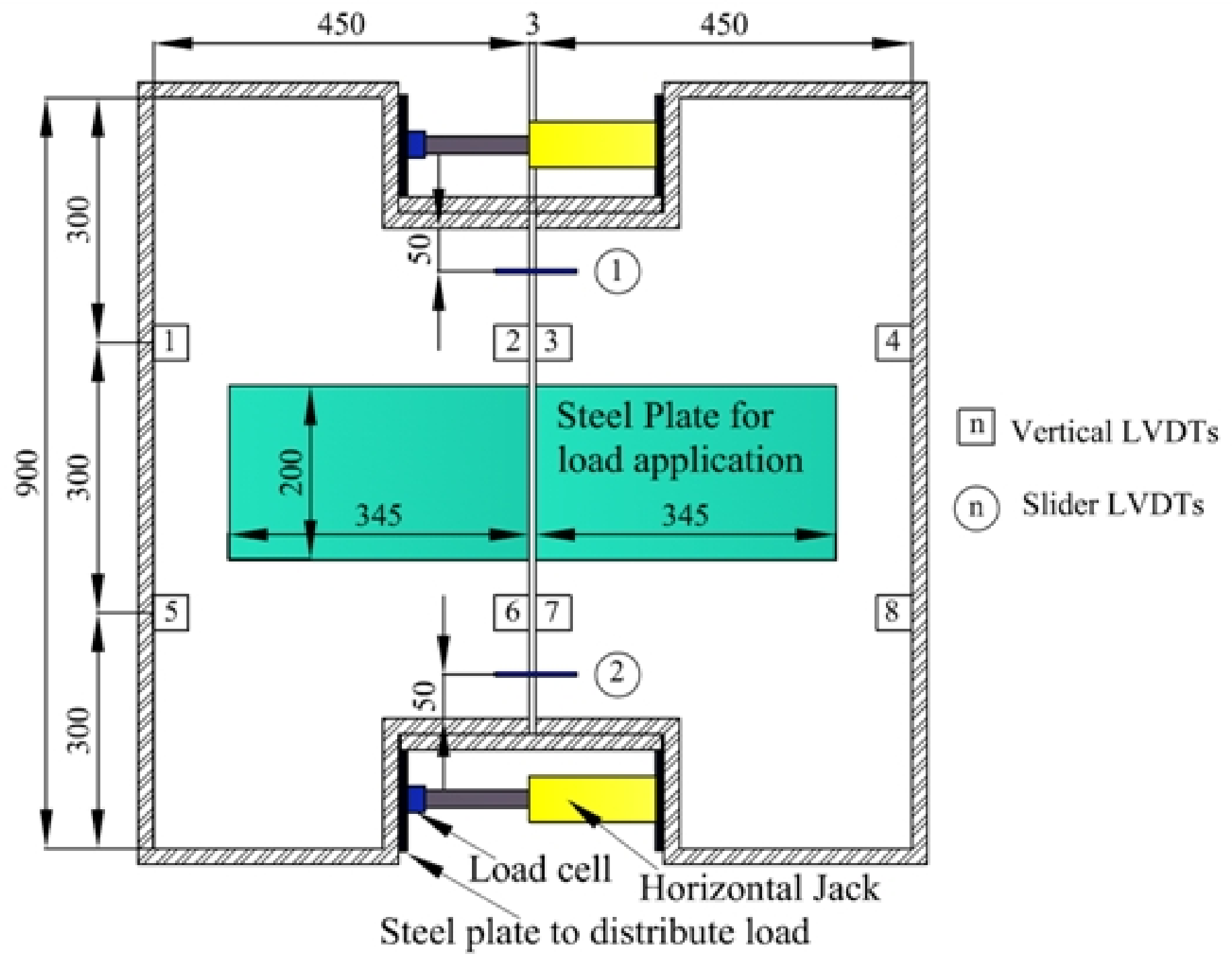

Fig.4. Sketch of a specimen with all instrumentations. 


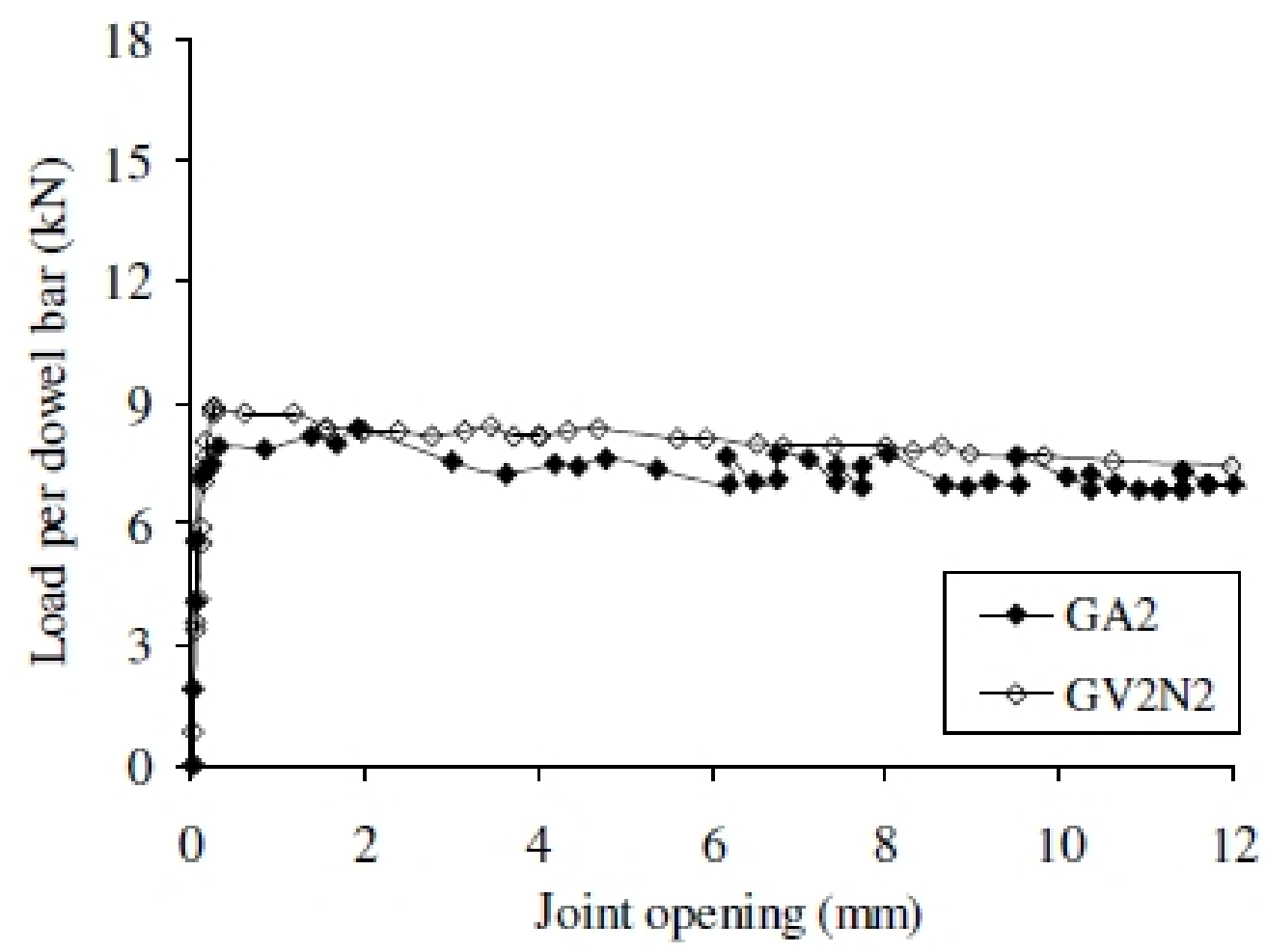

Fig.5. Effect of vertical misalignment for GFRP dowels - pullout load versus joint opening for the specimens GA2 and GV2N2 


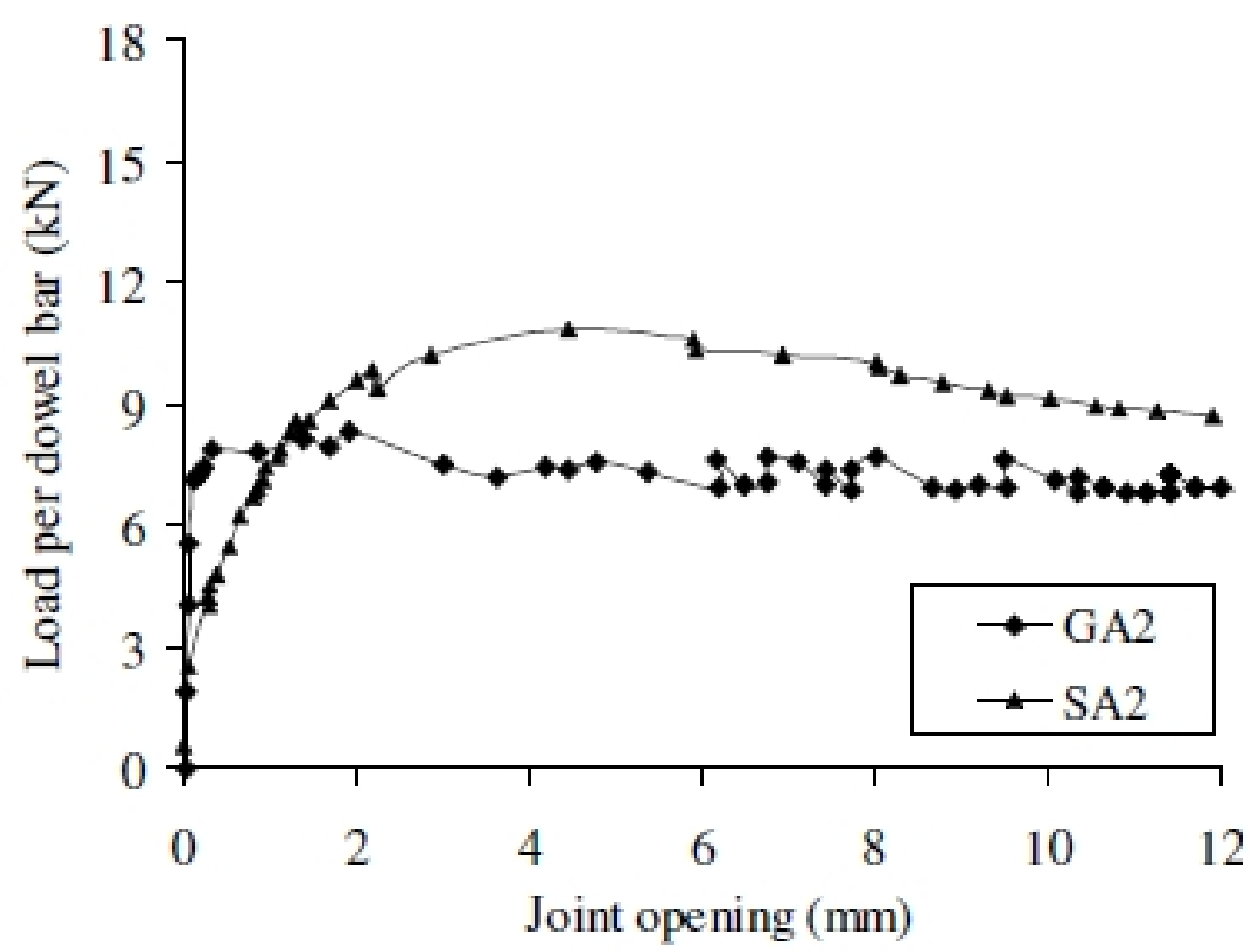

Fig.6. Comparison of aligned GFRP and steel dowels - pullout load versus joint opening for the specimens GA2 and SA2 


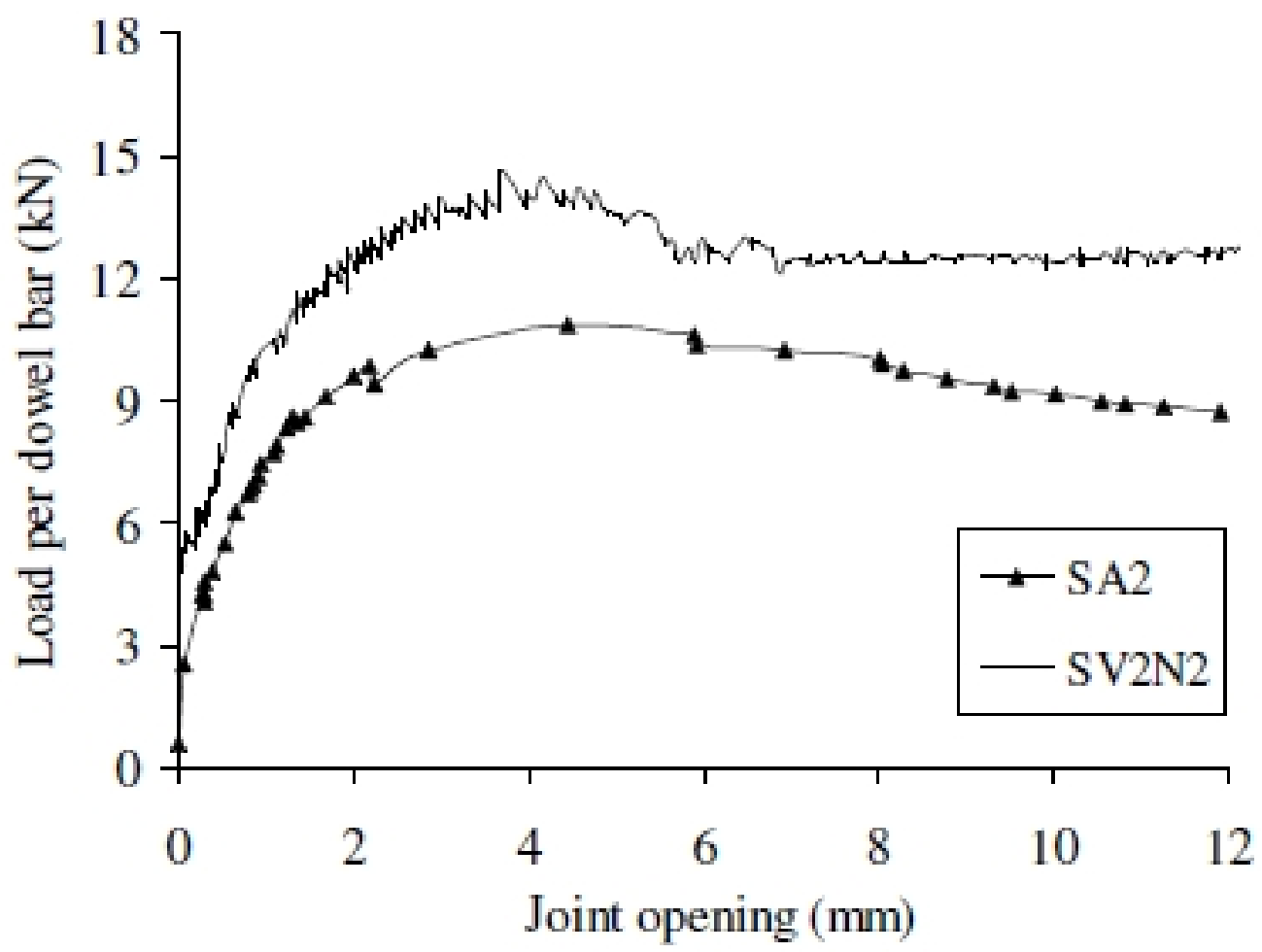

Fig.7. Effect of vertical misalignment for steel dowels - pullout load versus joint opening for the specimens SA2-steel and SV2N2 


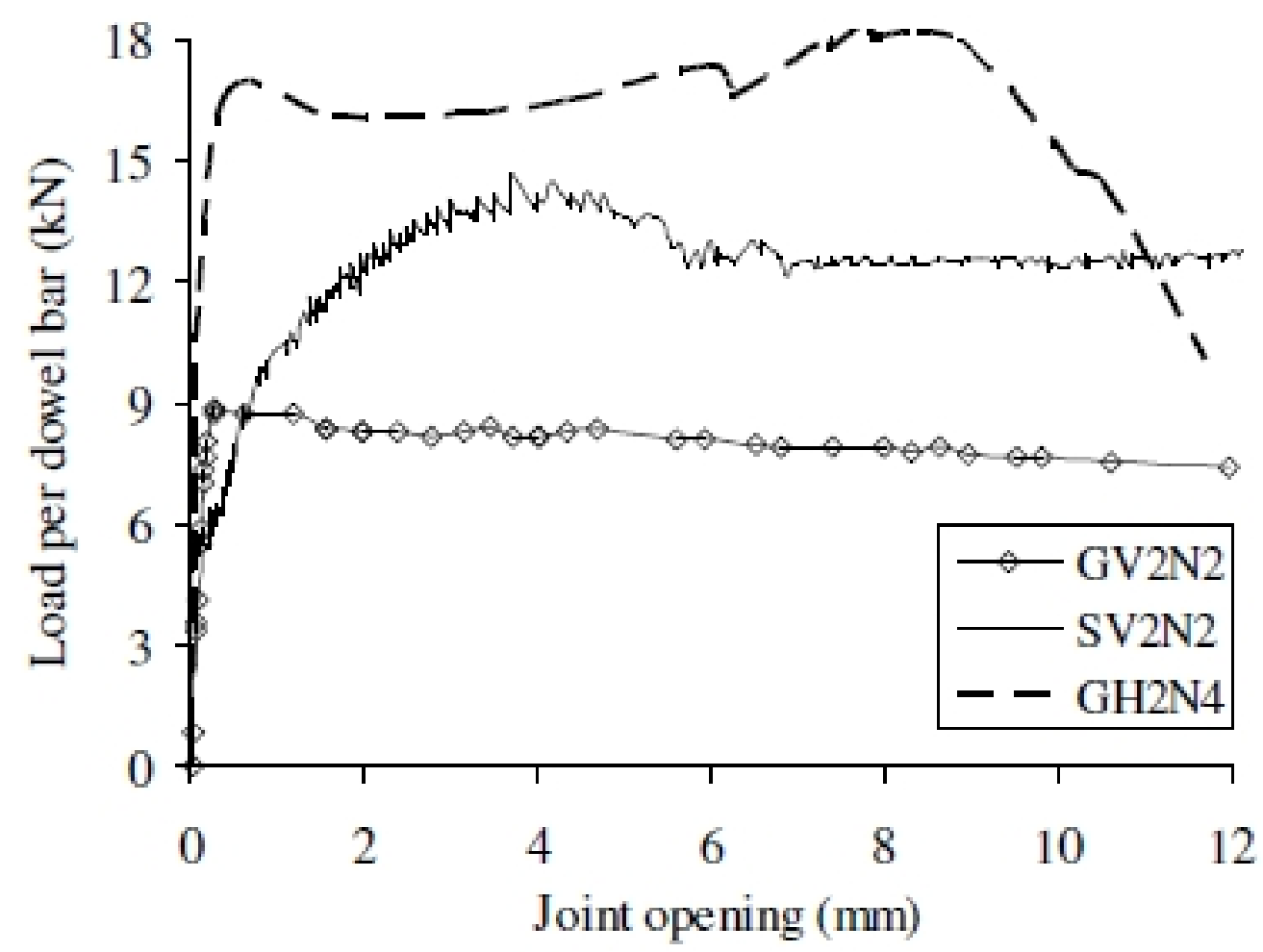

Fig.8. Comparison between horizontal and vertical misalignment - pullout load versus joint opening for the specimens of SV2N2, GV2N2 and GH2N4 


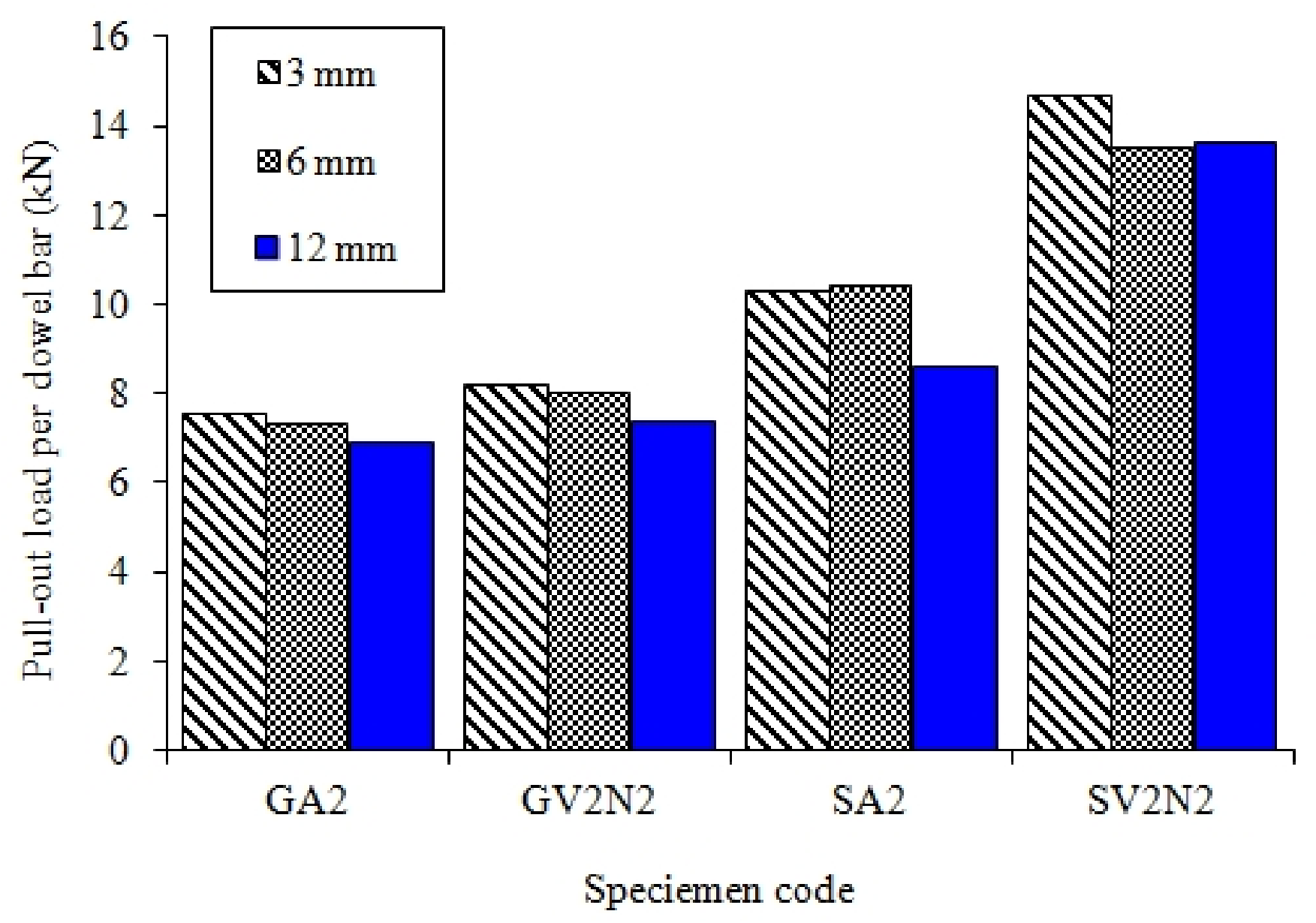

Fig.9. Comparison of pull-out loads for steel and GFRP at joint opening of $3 \mathrm{~mm}$, $6 \mathrm{~mm}$ and $12 \mathrm{~mm}$. 


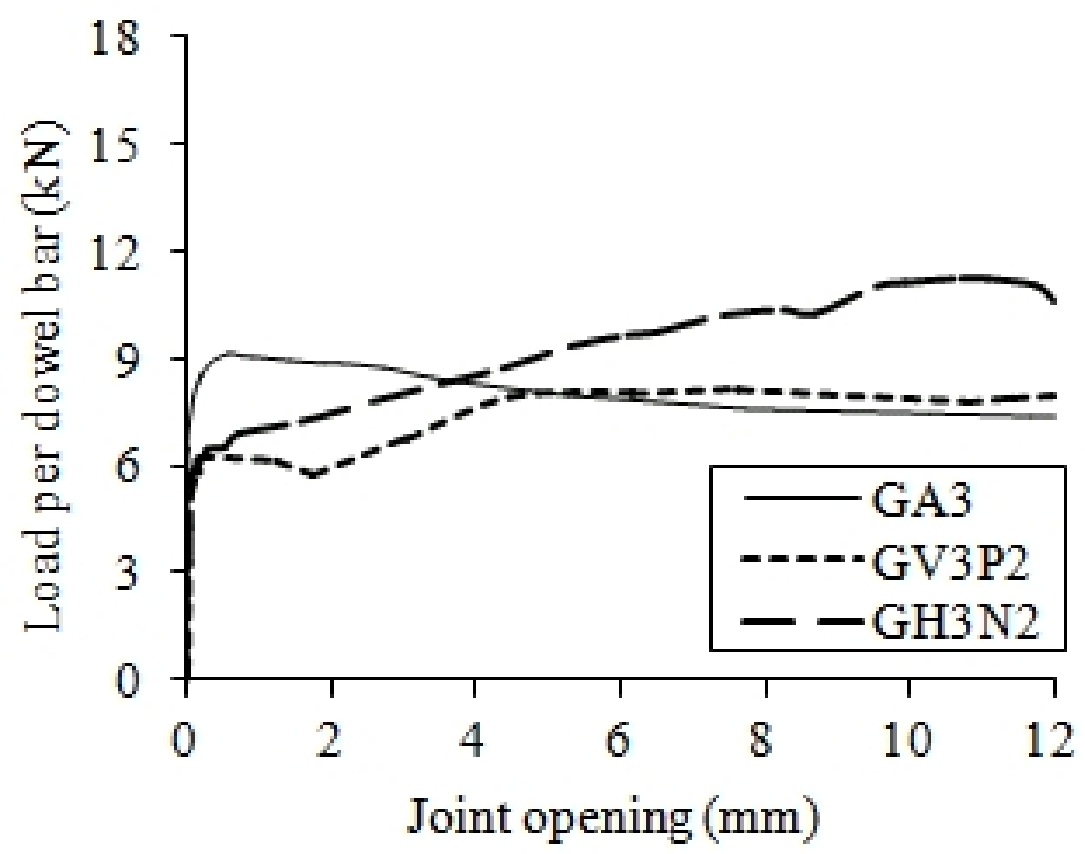

Fig. 10. Comparison of partial vertical and horizontal nonuniform misalignment with aligned dowels - pullout load versus joint opening for the specimens which have three 


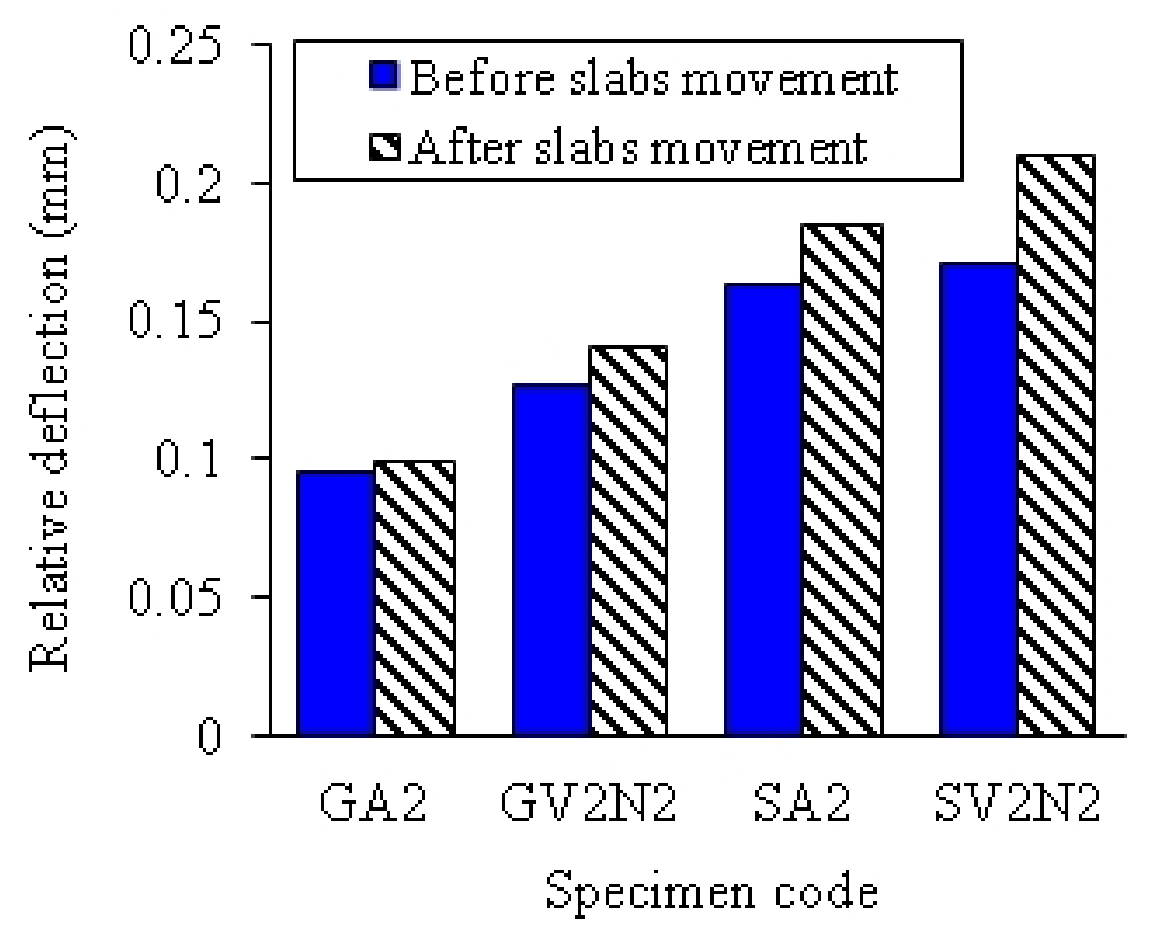

Fig.11. Comparison of relative deflection before, and after, slabs' movement. 


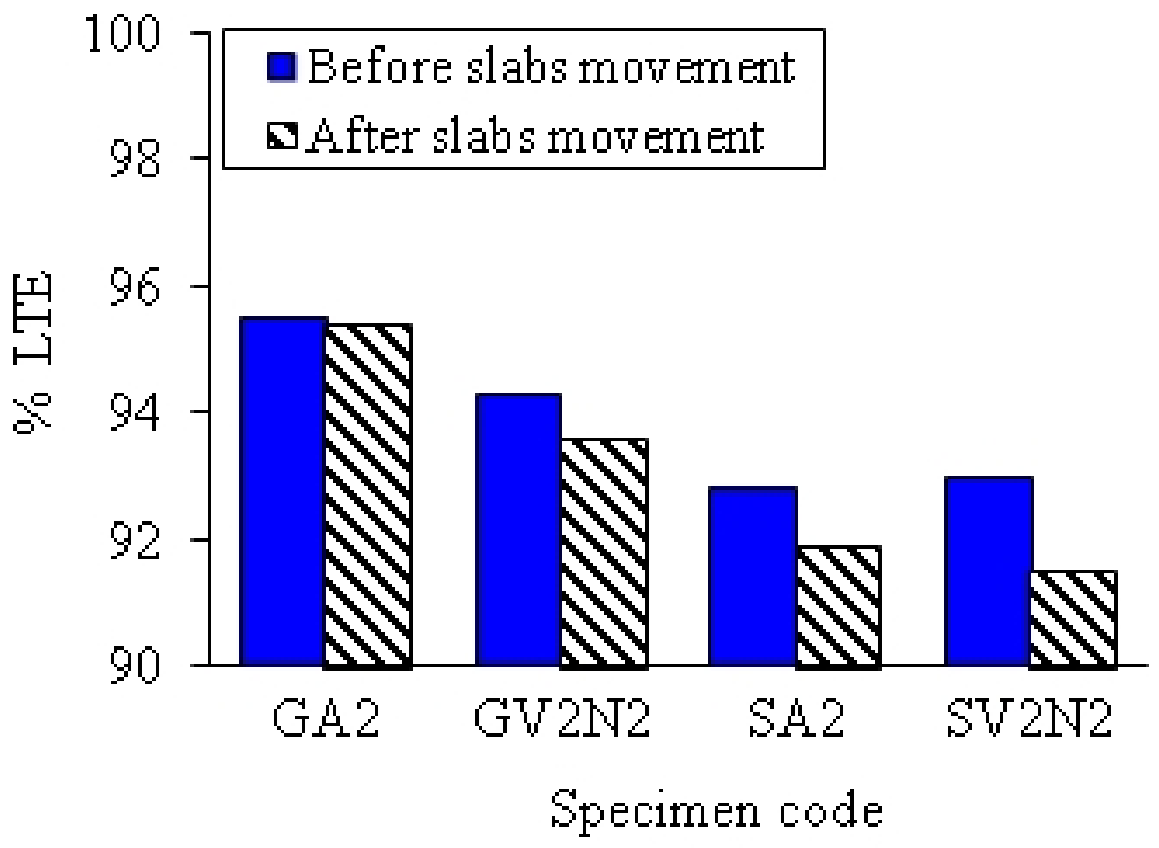

Fig. 12. Comparison of LTE before, and after, slabs' movement. 


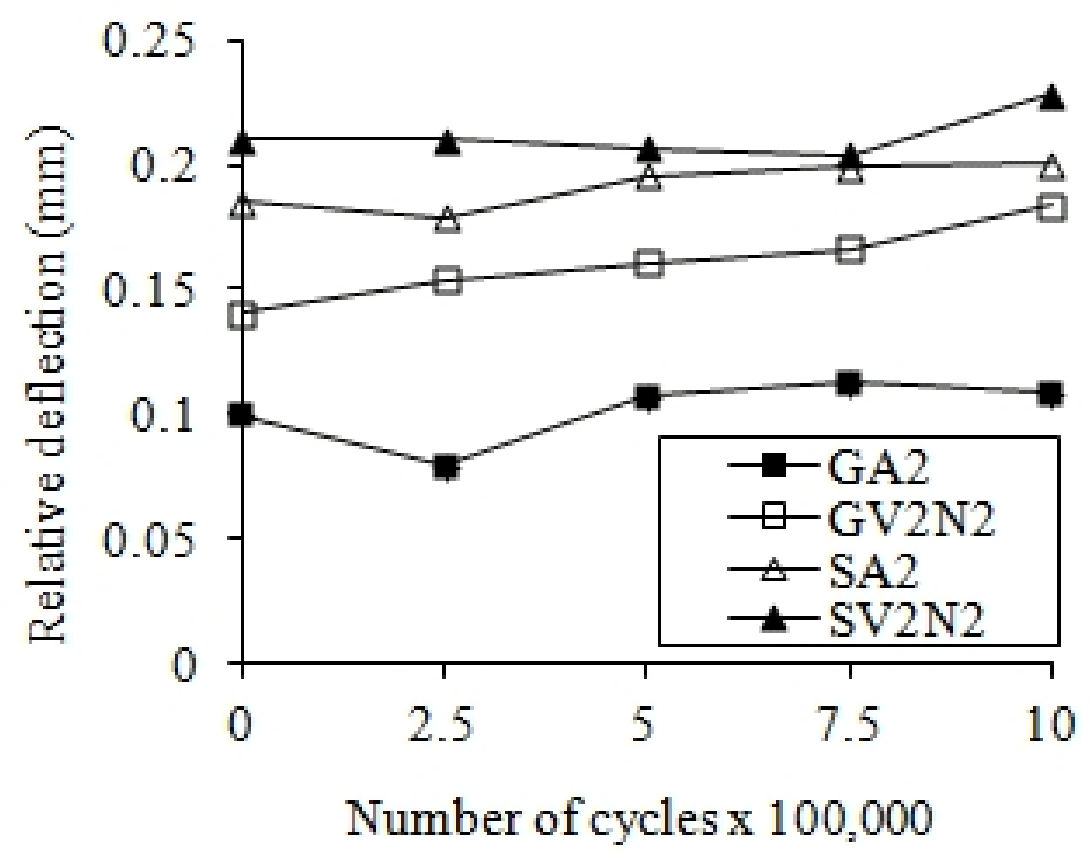

Fig. 13. Relative deflection versus number of load cycles. 


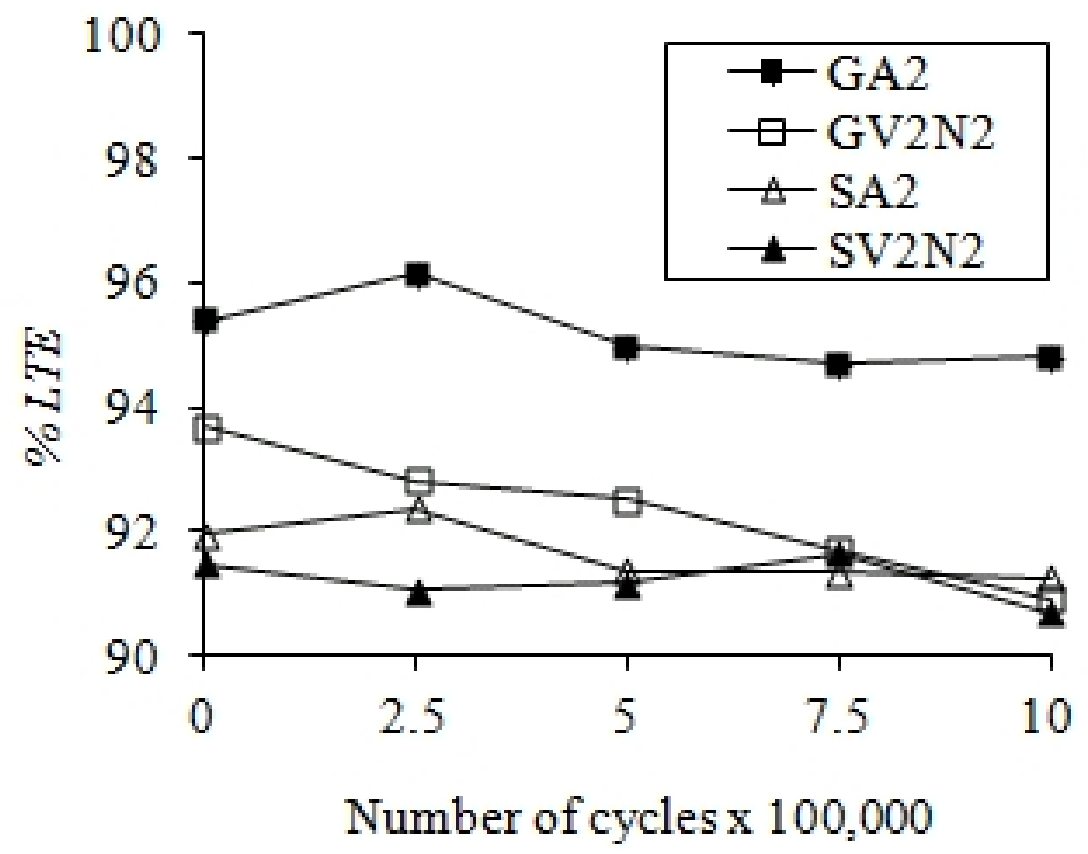

Fig. 14. LTE versus number of load cycles. 


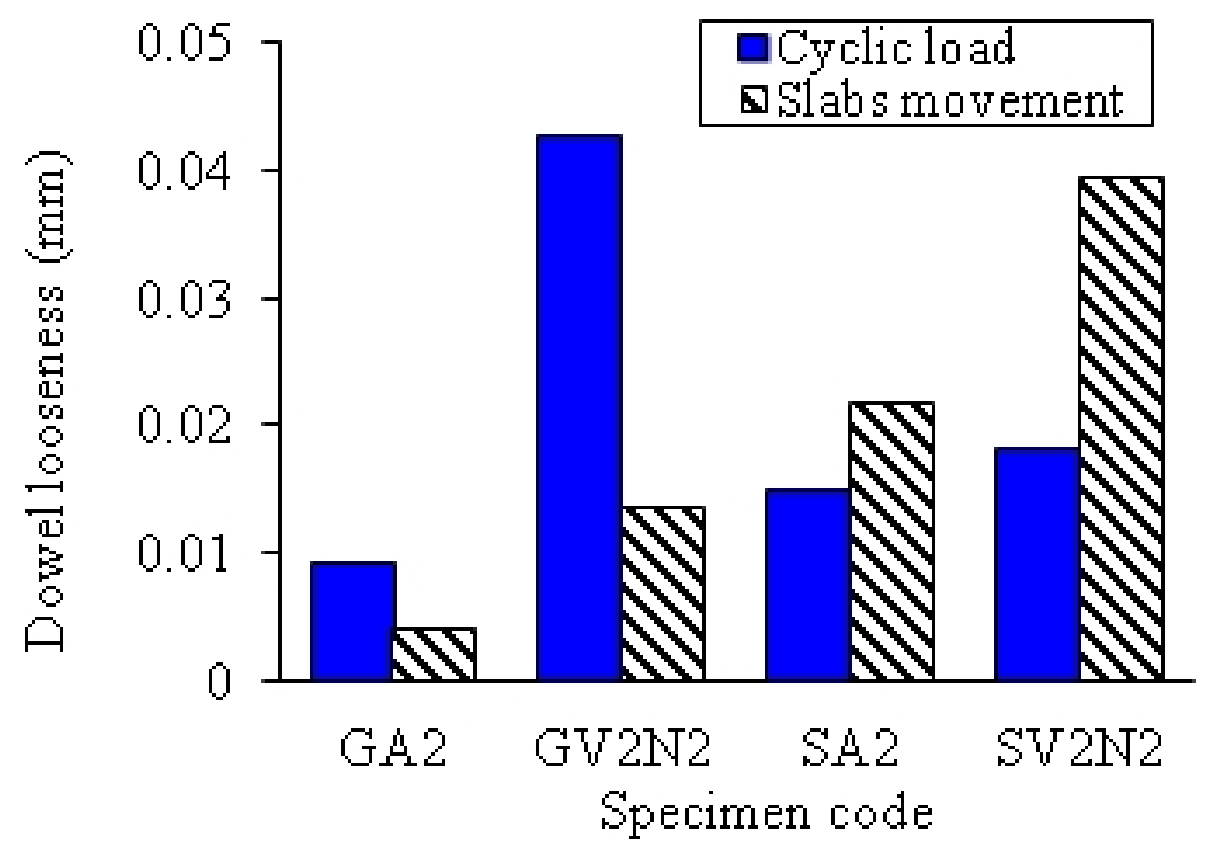

Fig. 15. Comparison of dowels' looseness due to slabs' movement and cyclic load. 
6

\begin{tabular}{ccccc}
\hline $\begin{array}{c}\text { Slab Dimensions } \\
(\mathrm{mm})\end{array}$ & $\begin{array}{c}\text { Number, diameter } \\
\text { and material of } \\
\text { dowel }\end{array}$ & $\begin{array}{c}\text { Code of } \\
\text { specimens }\end{array}$ & $\begin{array}{c}\text { Misalignment } \\
\text { type }\end{array}$ & $\begin{array}{c}\text { Magnitude of } \\
\text { misalignment per half } \\
\text { length of dowel }(\mathrm{mm})\end{array}$ \\
\hline 2 slabs each one & & GA2 & Aligned & 0 \\
$(450 \times 900 \times 200)$ & $2 \phi 38 \mathrm{~mm}$ GFRP & GH2N4 & Horizontal & 25 \\
& GV2N2 & Vertical & 12.5 \\
\cline { 3 - 5 } 2 slabs each on & $3 \phi 38 \mathrm{~mm}$ GFRP & GA3 & Aligned & 0 \\
$(450 \times 1200 \times 200)$ & GH3N2 & Horizontal & 12.5 \\
& & GV3P2 & Vertical & 12.5 \\
\cline { 3 - 5 } 2 slabs each one & $2 \phi 25 \mathrm{~mm}$ steel & SA2 & Aligned & 0 \\
$(450 \times 900 \times 200)$ & SV2N2 & Vertical & 12.5 \\
\hline
\end{tabular}

7

8

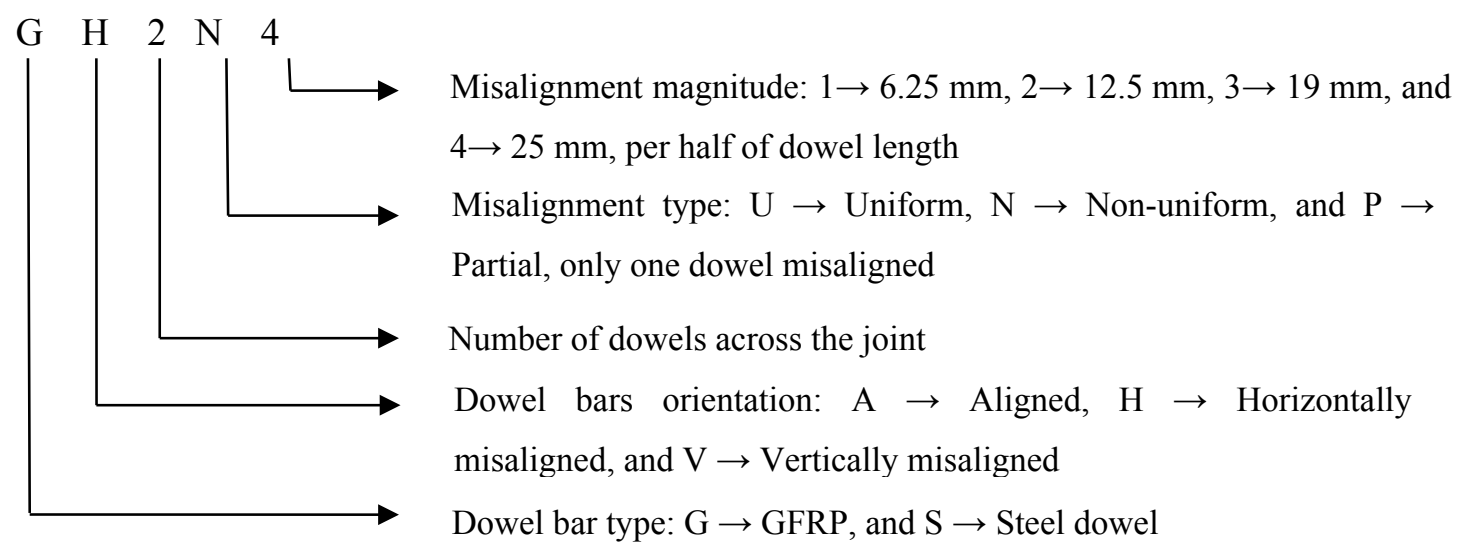

